\title{
The Role of Cyclooxygenase-2 in Cell Proliferation and Cell Death in Human Malignancies
}

\author{
Cyril Sobolewski, ${ }^{1}$ Claudia Cerella, ${ }^{1}$ Mario Dicato, ${ }^{1}$ Lina Ghibelli, ${ }^{2}$ and Marc Diederich ${ }^{1}$ \\ ${ }^{1}$ Laboratoire de Biologie Moléculaire et Cellulaire du Cancer, Hôpital Kirchberg, 9 rue Edward Steichen, \\ 2540 Luxembourg, Luxembourg \\ ${ }^{2}$ Dipartimento di Biologia, Università di Roma di Roma Tor Vergata, Via Ricerca Scientifica snc, 00133 Rome, Italy
}

Correspondence should be addressed to Marc Diederich, marc.diederich@lbmcc.lu

Received 16 July 2009; Accepted 18 December 2009

Academic Editor: Simone Fulda

Copyright ( $) 2010$ Cyril Sobolewski et al. This is an open access article distributed under the Creative Commons Attribution License, which permits unrestricted use, distribution, and reproduction in any medium, provided the original work is properly cited.

It is well admitted that the link between chronic inflammation and cancer involves cytokines and mediators of inflammatory pathways, which act during the different steps of tumorigenesis. The cyclooxygenases (COXs) are a family of enzymes, which catalyze the rate-limiting step of prostaglandin biosynthesis. This family contains three members: ubiquitously expressed COX1 , which is involved in homeostasis; the inducible COX-2 isoform, which is upregulated during both inflammation and cancer; and COX-3, expressed in brain and spinal cord, whose functions remain to be elucidated. COX-2 was described to modulate cell proliferation and apoptosis mainly in solid tumors, that is, colorectal, breast, and prostate cancers, and, more recently, in hematological malignancies. These findings prompt us to analyze here the effects of a combination of COX-2 inhibitors together with different clinically used therapeutic strategies in order to further improve the efficiency of future anticancer treatments. COX2 modulation is a promising field investigated by many research groups.

\section{Introduction: Inflammation and Cancer are Linked}

Inflammation is the major reaction of natural immunity with the goal to defend the organism against pathogens. It can be induced upon bacterial infections by compounds including lipopolysaccharides, as well as by viruses, which are detected by Toll-like receptors (TLRs), expressed by immune cells like macrophages. Besides, inflammation can be triggered by physical injuries (i.e., UV) or chemical compounds (i.e., reactive oxygen species) [1]. The activation of specific receptors triggers intracellular signals (i.e., NFkB, p38, or MAPKsmediated), which regulate pro-inflammatory cytokine expression, such as interleukin 1 beta (IL1 $\beta)$, tumor necrosis factor alpha (TNF $\alpha$ ), interleukin 6 (Il6), together with chemokines and cell adhesion proteins [1], in turn, leading to the recruitment and the activation of immune cells.

Several diseases are associated to chronic inflammation, such as osteoarthritis, Crohn's disease, and cancer [2]. Although the first evidence of a connection between inflammation and cancer dates back to more than a century ago [3], only recently, this link has been further investigated, thus evidencing that the incidence of several cancers is tightly associated to inflammation such as colon, breast, and prostate cancers [4-6]. This hypothesis is supported by the findings that the tumor microenvironment is characterized by the infiltration with different types of immune cells (i.e., dendritic cells, lymphocytes, and macrophages) responsible for the release of cytokines [1]. The role of these cytokines in tumor incidence has been established in many studies. For example, the overexpression of TNF $\alpha$ in transgenic mice bearing a lung tumor is associated with an increase of the size of the tumor [7]. Moreover, a chronic intake of nonsteroidal antiinflammatory drugs (NSAIDs) leads to a significant reduction in the incidence of such tumors. Colorectal cancer (CRC), which remains an important cause of death in the industrialized world, is one of the most characterized types of tumor that benefits from treatment by NSAIDs [8]. Interestingly, chronic use of aspirin is reported to reduce the relative risk of CRC by about 50\% [9]. Familial adenomatous polyposis, an inherited form of colon cancer, is characterized by the development of preneoplastic polyps. 
At the molecular level, this disease is caused with a mutation of a tumor suppressor gene called Adenomatous polyposis coli (APC). It has been shown that the use of NSAIDs, like sulindac, as a chemopreventive treatment, is able to decrease the incidence of polyp formation [10]. Similar results were obtained with celecoxib [11], which is now approved by the Food and Drug Administration's Oncologic Drugs Advisory Committee as an adjuvant in FAP therapy.

A body of evidence indicates a role for inflammation in the development/modulation of different steps of cancer progression. Inflammation may play a role in tumor initiation by triggering the production of reactive oxygen species (ROS), responsible for DNA damage, thus increasing the rate of mutations [12]. It may also be implicated in tumor promotion, where inflammation triggers the secretion of growth factors, such as the epithelial (EGF) and fibroblast growth factors (FGF). These, in turn, favor the proliferation of initiated tumor cells by determining an imbalance between cell proliferation and cell death stimuli [6], due to the activation of different cell survival pathways [7].

Besides, the different cytokines produced during inflammation (i.e., TNF $\alpha$, IL1 $\beta$, IL6, and IL8) can also activate several survival pathways, thus leading to an escape of tumor cells from cell death. Well known is the case of $\mathrm{TNF} \alpha$, produced by tumor and immune cells, which leads to the survival of cancer cells by the upregulation of antiapoptotic proteins, that is, $\mathrm{Bcl}-2$ [13-15], via the activation of the nuclear factor kappa $B(\mathrm{NF} \kappa \mathrm{B})$ [16]. The modulation of pro-survival pathways or anti-apoptotic proteins makes the expression/activation of such proinflammatory mediators also a determining factor in chemoresistance. A constitutive activation of such proinflammatory factors has been frequently found in many cancers, such as hepatocellular carcinoma [17], prostate cancer [18], as well as chronic and acute myeloid leukemia [19], where it is frequently associated with a bad prognosis. In these instances, the modulation of Bcl-2 anti-apoptotic family members has been frequently shown $[13-15,20]$.

Amongst the different mediators of inflammation, the cyclooxygenases (COXs) clearly appear to be implicated in cancer. This review focuses on COX-2, the inducible form, normally induced and implicated in inflammation, and intends to analyze what is currently known about the link between COX-2 and cancer, in terms of effects on cell proliferation and cell death. In this view, we will focus our attention on studies analyzing the effects of COX-2 inhibitors on cancer cells, when used alone as well as in combination with therapeutic approaches, including radiotherapy, chemotherapeutic agents, and photodynamic therapy. Finally, we will consider the relevance of COX-2-independent effects.

\section{The Cyclooxygenase Enzyme Family}

Cyclooxygenases (or prostaglandin $\mathrm{H}$ synthases), commonly referred to as COXs, are a family of myeloperoxidases located at the luminal side of the endoplasmic reticulum and nuclear membrane [21], which catalyze the rate-limiting step of prostaglandin biosynthesis from arachidonic acid [21]. These enzymes act by two coupled reactions. The first one is the conversion of arachidonic acid released from the plasma membrane by phospholipase A2 to prostaglandin G2 by the cyclooxygenase activity. The second reaction is mediated by the peroxidase activity and leads to the conversion of prostaglandin G2 to prostaglandin $\mathrm{H} 2$. Then, different synthases convert prostaglandin $\mathrm{H} 2$ to prostaglandin $\mathrm{D} 2$, F2 $\alpha$, E2, I2, and thromboxane A2 (Figure 1).

Prostanoids (prostaglandins and thromboxanes) are immediately released from the cells, where it is believed that they act locally in an autocrine and paracrine manner through different receptors activating different intracellular pathways still to be completely elucidated (Figure 1) [22]. Prostaglandins, specifically, are important for physiological functions like vasodilatation (PGD2, PGE2, PGI2), gastric cytoprotection (PGI2), maintenance of renal homeostasis, and platelet aggregation. Besides, prostaglandins play a major role in mediating fever (PGE2), pain sensitivity, and inflammation [21].

So far, three isoforms of COXs have been identified. Cyclooxygenase- 1 (COX-1) is a glycoprotein of $71 \mathrm{kDa}$, which is constitutively expressed in different tissues. COX-1 is encoded by a gene on chromosome 9 and plays a role in tissue homeostasis by modulating several cellular processes ranging from cell proliferation to angiogenesis or platelet aggregation due to thromboxane production [21].

Cyclooxygenase-2 (COX-2) is the inducible isoform, which is regulated by growth factors and different cytokines such as IL1 $\beta$, IL6, or TNF $\alpha$ [23], therefore overexpressed during inflammation. The COX-2 gene is located on chromosome 1 and its promoter displays an $\mathrm{NF} \kappa \mathrm{B}$ response element as well as other cytokine-dependent (i.e., IL6) response elements [21]. The protein shows a $60 \%$ homology with COX-1 [24]; in addition, COX-2 presents a C-terminal extension and a different binding site for NSAIDs, which makes COX-2 a preferential target compared to COX-1, thus being specifically inhibited at lower doses [25].

Finally, COX-3 has been identified as a splice variant of COX-1, and it is present mainly in brain and spinal cord $[26,27]$. Currently, the role of COX-3 is not known. Some pieces of evidence suggest a possible role in pain sensitivity, based on studies focused on the mechanism of action of acetaminophen (paracetamol), recently evoked as a selective inhibitor of COX-3 [28]. However, this hypothesis is debated because other findings argue that acetaminophen targets at the same time COX-2 [29].

\section{COX-2 As a Tumor Promoter and a Good Candidate for Cancer Therapy}

Overexpression of COX-2 has been detected in a number of tumors, such as colorectal breast as well as pancreatic and lung cancers $[2,30-32]$, where it correlates with a poor prognosis. Moreover, overexpression of COX-2 has been reported in hematological cancer models such as RAJI (Burkitt's lymphoma) and U937 (acute promonocytic leukemia) [33,34] as well as in patient's blast cells [32, 34]. Data suggested that COX-2 may play a role in different steps of cancer progression, by increasing proliferation of mutated cells [30], thus favoring tumor promotion as well as by 


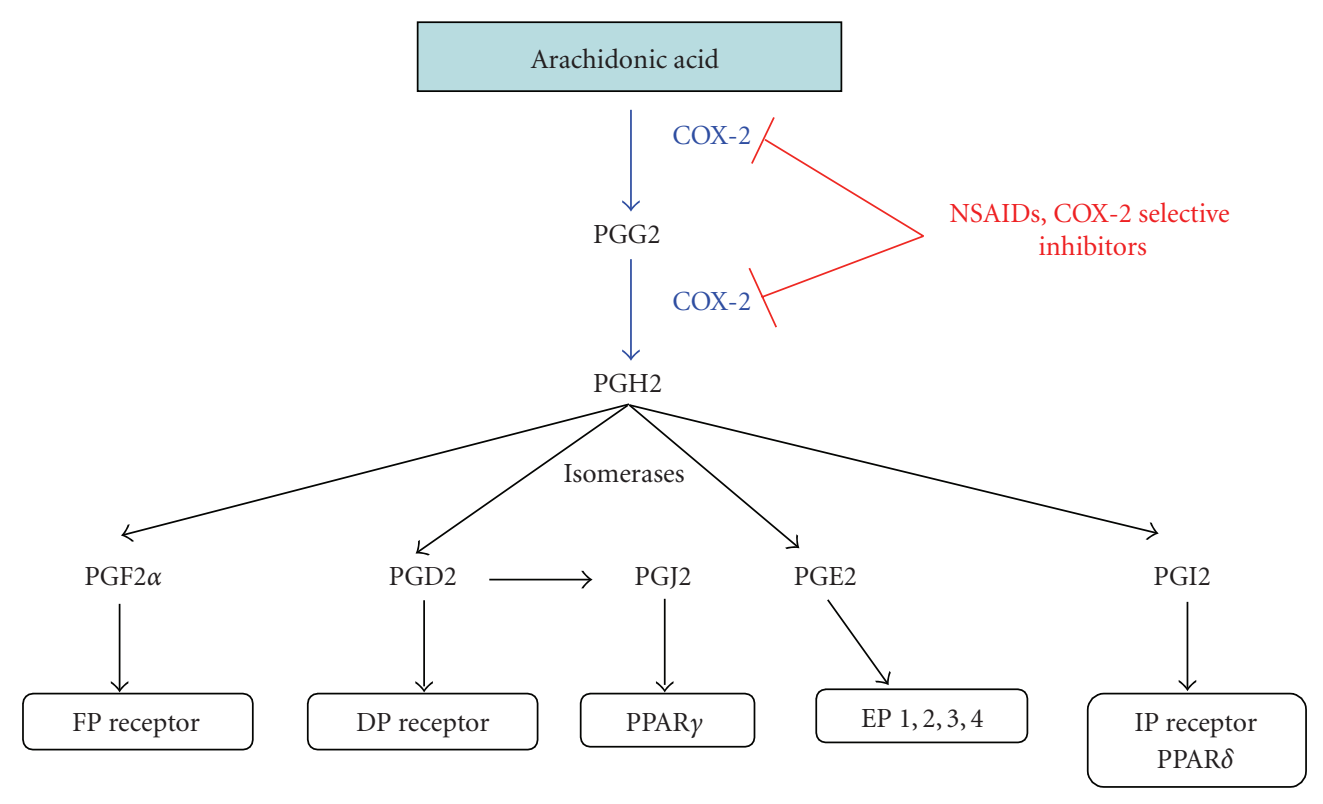

FIGURE 1: Metabolism of arachidonic acid by COX-2 and receptors implicated in response to prostaglandins (according to Chandrasekharan et al. [21]). Prostaglandins act through different receptors to mediate their effects. PGE2 is able to bind four receptors (EP1, 2, 3, and 4). These receptors do not possess the same ligand affinity and their expression is tissuedependent. The different receptors are associated with different intracellular pathways. Most of these receptors are localized in the plasma membrane but nuclear receptors PPAR $y$ can also bind PGJ2. Abbreviation: COX-2, cyclooxygenase-2; PG, prostaglandin; FP, prostaglandin F receptor; DP, prostaglandin D receptor; EP, prostaglandin E receptor; IP, prostaglandin I receptor; PPAR, peroxisome proliferator-activated receptor; NSAIDs, nonsteroidal anti-inflammatory drugs.

affecting programmed cell death and affecting the efficacy of anticancer therapies [35-39] to be, finally, implicated in metastasis formation, for example, by affecting apoptosis induced by loss of cell anchorage (anoikis) [40].

COX-2 induction or overexpression is associated with an increased production of PGE2, one of the major products of COX-2 which is known to modulate cell proliferation, cell death, and tumor invasion in many types of cancer including colon, breast, and lung. Prostaglandin E2 acts through different membrane receptors called EP receptors (EP1, EP2, EP3, and EP4) [41]. These receptors are all located on the cell surface and characterized by seven-transmembrane domains, and rhodopsin-type $G$ protein-coupled receptors, but trigger different signaling pathways. Thus, it is known that EP1 signaling acts through phospholipase C/inositol triphosphate signaling, leading to intracellular mobilization of calcium. EP2 and EP4 receptors are coupled with G proteins which activate adenylate cyclase, leading to an increase of intracellular cAMP [41]. cAMP is then able to activate kinases such as protein kinase A (PKA) or PI3K for example, and also GSK3 leading to an activation of $\beta$-catenin, a pathway regulating cell proliferation $[42,43]$. In contrary to EP2 and EP4, EP3 is coupled with Gi protein, leading to an inhibition of adenylate cyclase, and thus a decrease of cAMP inside the cells [41]. The differential expression of these different receptors according to the cell type may explain the diverse and antagonist effects of PGE2 described in literature.

Until now, there are multiple evidences about the role of PGE2 in tumorigenesis in some cancers. These evidences are mostly described for adherent tumors while this link is poorly understood for hematopoietic malignancies such as leukemia or lymphoma. Indeed, several papers have reported that PGE2 is the most important prostaglandin produced during colorectal carcinogenesis [44]. Moreover, it is known that the level of PGE2 increases in a size-dependent manner in Familial Adenomatous Polyposis (FAP) patients [45], suggesting a correlation between tumor growth and prostaglandin biosynthesis. Tumorigenesis is characterized by a disequilibrium between cell proliferation and cell death. PGE2 is able to inhibit apoptosis in human colon cancer cells. It has been demonstrated that PGE2 can upregulate the level of the anti-apoptotic protein Bcl-2 in HCA-7 cells (adenocarcinoma), which produce significant amounts of PGE2. This paper described a modulation of the MAPK pathway that precedes the upregulation of Bcl-2 [46]. PGE2 can mediate its effect through EGF receptor, leading to MAPK activation. The ability of PGE2 to modulate tumor progression in colorectal cell has been shown in other models of colon cancer such as HT-29 cells that express EP receptors. In this cell type, PGE2 is associated with an increase of cAMP through EP4 receptor. The effect can be reversed by L-161982, an antagonist of EP4 [47]. Moreover, PGE2 transactivates EGFR by triggering the release of amphiregulin, a well-known EGFR ligand [48]. SC-236, an inhibitor of COX-2, is able to inhibit cell proliferation of HT-29 cells and this effect is greater in combination with an amphiregulin neutralizing antibody [47]. In this cell line, the expression of amphiregulin is correlated to the expression of COX-2. 
The transactivation of EGFR by PGE2 can lead also to AKT activation, which is a well-known survival pathway [49]. This effect was well described in a study by Tessner et al. [50] demonstrating that 16,16-dimethyl PGE2 (dmPGE2) inhibits radiation-induced apoptosis in the mouse intestinal epithelium. Using HCT-116 cell line as a model to reflect the effect on mouse small intestine, it has been shown that the anti-apoptotic effect of dmPGE2, which is known to bind EP2, was tightly related to AKT phosphorylation through activation of EGFR and leads to an inhibition of Bax translocation in mitochondria, an important step for apoptosis [51].

PGE2 modulates also tumor growth of lung cancer. This effect has been described by Yamaki et al. [52] showing that PGE2 activates Src kinase in A549 cells, leading to an induction of cell growth. These cells express EP3 that activates Src (sarcoma) kinase. This study has demonstrated that the activation of Src leads to an activating phosphorylation of STAT3, a transcription factor known to regulate cyclin D1 transcription, an important positive regulator of cell proliferation. Apoptosis can be inhibited because STAT3 regulates the transcription of $\mathrm{Bcl}-\mathrm{XL}$, a well-known anti-apoptotic protein [53]. Moreover, Src phosphorylates p27, a protein known to inhibit cell cycle progression especially at the G1/S transition [54]. However, it has been recently shown that this protein plays a dual role as the unphosphorylated form of p27 inhibits the cell cycle, and thus cell proliferation. If phosphorylation occurs on T157 and T198 by PI3K (phosphoinositide 3-kinase), it triggers cell cycle transition by stabilizing the cyclin D1/cdk4 complex [55]. Thus phosphorylation of S10 appears to be important for other phosphorylation steps and it has been hypothesized that Src kinase can play this role [55]. Moreover, it is known that phosphorylation of p27 is responsible also for its degradation by the proteasome [56]. All together these data suggest that PGE2 increases cell proliferation via p27 phosphorylation through EP4 receptors.

Nonsmall lung cancer is characterized by a Ras mutation correlated with a poor prognosis [57]. Activation of Ras leads to an upregulation of COX-2 resulting in increased PGE2 production [58]. PGE2 increases cell proliferation of A549 cells (adenocarcinoma) and this effect is associated with an activation of Ras pathway via EP4 receptor. In this case, PGE2 mediates its effect by the release of amphiregulin, the most abundant ligand in A549 cells [59]. EGFR activation leads to activation of MAPK pathway that regulates cell proliferation by transactivating several oncogenes such as c-myc [60].

PGE2 is also important for tumor invasion. A study by Ma et al. [61] described that PGE2 can increase the number of metastasis. This effect has been demonstrated in a model in which murine mammary tumor cells 66.1 were injected in syngenic immune competent BALB/CByJ mice. All these cell lines express EP1, 2, 3, and 4. The use of EP4 antagonists (AH23848 and AH6809) decreased surface tumor colonies and reduced tumor invasion. Another study has revealed that PGE2 increases the level of VEGF in granuloma [62]. VEGF is an important factor of angiogenesis, and thus of tumor progression by enhancing the vascularization of the tumors [63].
Alltogether these data together suggest that PGE2 and, thus, COX-2 play an important role in tumor progression by enhancing cell proliferation, cell survival, and tumor invasion. The diversity of PGE2 receptors and their different signaling pathways suggest that the protumorigenic effect of PGE2 depends on the cell type and the type of receptor expressed. Until now, many signaling pathways associated with tumor progression are linked to PGE2 and this could explain why the use of COX-2 inhibitors is a good strategy in cancer therapy. However, the signaling pathways of EP receptors are not completely characterized and their precise roles in the different cancers remain to be elucidated before a clinical application.

COXs may be targets of several compounds that may inhibit their functions. Combination of such preferential or selective COX-2 inhibitors with anti-cancer agents already used in clinics were tested with the goal to improve the efficiency of anti-cancer protocols.

COX-2 is the preferential target of several NSAIDs (Figure 2) $[64,65]$. Historically, NSAIDs used for clinical and anti-inflammatory purposes were represented by the nonselective COX-2 inhibitors, to which belong aspirin, sulindac acid and, more recently, agents such as nimesulide, ibuprofen and naproxen. As their definition well reflects, this first generation of NSAIDs may affect both main COXs isoforms, even if preferentially COX-2 (see above). Their mechanisms of action are not all completely elucidated, complicated by the fact that different agents seem to act in different ways. For example, different NSAIDs bind the active site of COX2. Commonly, binding occurs by a reversible competitive inhibition (i.e., ibuprofen, naproxen, and indomethacin). In contrast, aspirin is able to acetylate the active site of COX at a serine residue, leading to an irreversible inhibition (see Figure 2, summarizing the classification of COX-2 inhibitors mentioned in this review). Considerable side effects generated by the interference with homeostatic functions modulated by COX-1 include increased incidence of gastrointestinal hemorrhage and ulceration upon chronic or long-time intake [66]. A novel generation of COX-2-selective inhibitors NSAIDs termed "Coxibs" was then developed. These compounds promised to be much less gastrotoxic. They act as competitive inhibitors of the active site of COX-2 and present indeed a higher specificity. However, concerns related to a long-time/chronic intake of these drugs raised quite soon, following some clinical reports, suggest a correlation between an increased risk of myocardial infarction and their consumption [67]. This has lead to the voluntary withdrawal of some of these agents, that is, rofecoxib and valdecoxib [68], and drastic regulatory advices regarding the use of the other ones, thus opening a discussion on the real benefits versus side effects of their use in clinics. Consequently, studies focused on the use of traditional versus COX-2-selective NSAIDs, frequently associated to the elaboration of economical models, have been performed in these latest years, with the aim to evaluate the real risks together with the costeffectiveness and, possibly, identify classes of users/patients where regular NSAIDs intake may be beneficial. Although, further analyses need to be performed, a number of reports suggest that Coxibs may really increase 


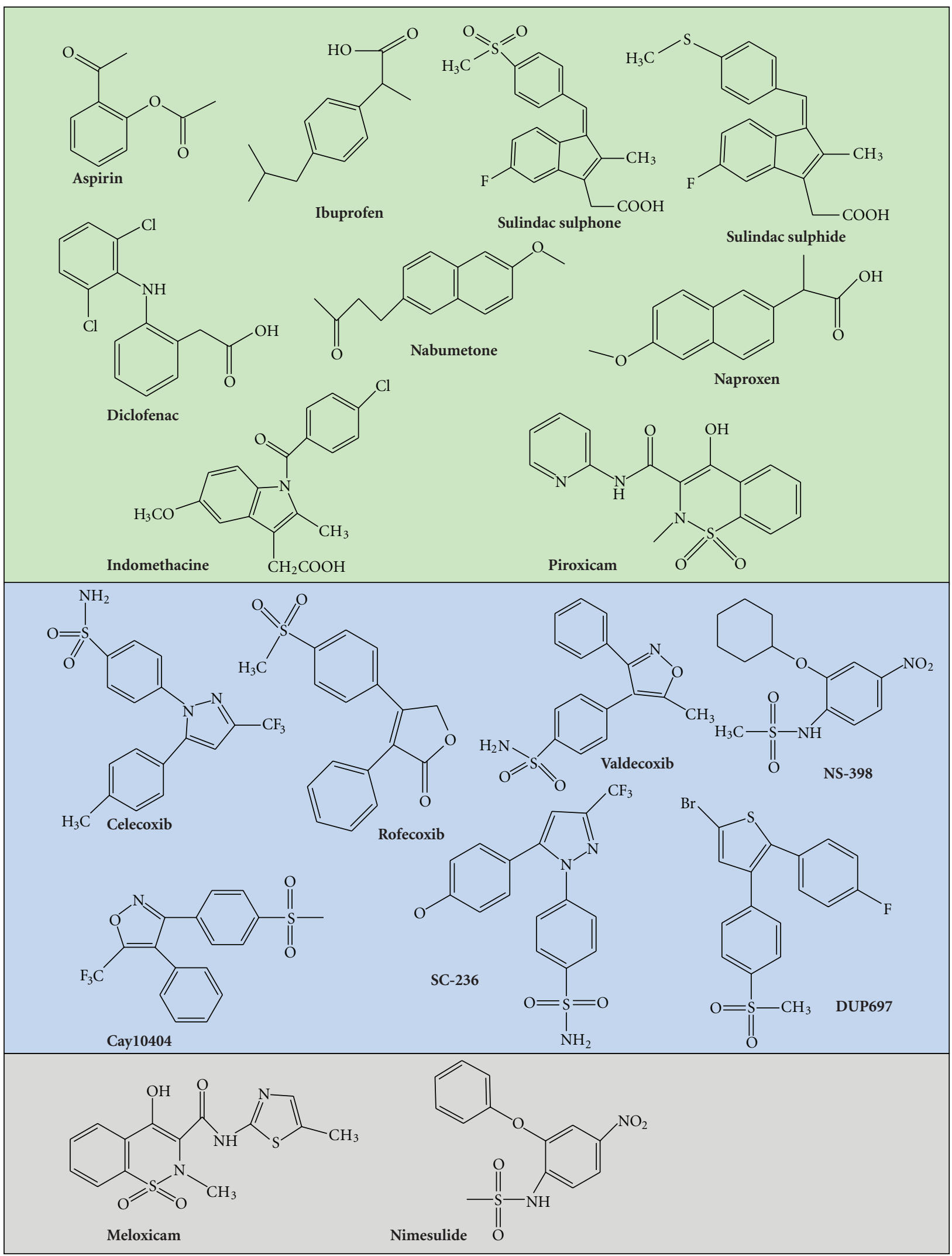

FIGURE 2: COX-2 inhibitor classification. COX-2 is the target of many compounds. COX-2 inhibitors described in this review are classified according to their ability to inhibit COX-2: nonselective (green), selective (pale blue), and preferential (grey). 
cardiovascular risks only in patients presenting a positivity to other cardiovascular factor risks, as high blood pressure and altered lipid metabolism [69-73]. These results suggest that their use should be limited to patients with a low risk of cardiovascular complications after analysis of multiple biomarkers [Chaiamnuay et al., 2006, clinical reviews]. Therefore, the future perspective in the pharmacological use of preferential versus selective COX-2 inhibitors is the identification of a panel of interesting biomarkers, helping in defining individual biological risk factors and limiting the use of a specific class of COX-2 inhibitors to the appropriate responders $[74,75]$. This approach will have a considerable implication in therapy as well as in chemoprevention of inherited forms of colon cancer.

It is interesting to mention that recent alternative approaches have been considered. Strillacci et al. [76] and Chan et al. suggested RNA interference using adenoviral vehicles. Moreover, other selective COX-2 inhibitors have been developed and experimentally used: SC-558 [35], DUP-697 [77], SC-58125 [78], and NS-398 [8]. Some of them induce an irreversible inhibition. This is the case for NS-398, which acts by inducing a conformational change of COX-2 [25] (Figure 2). Another strategy discussed in literature could be the use of EP receptor antagonists. Indeed, it has been demonstrated that EP antagonists can decrease cell proliferation and cell invasion $[47,61,79]$. This could be a more specific strategy that could limit the other side effects of classic COX-2 inhibitors.

\section{COX-2 As a Regulator of Cell Proliferation}

Cell cycle is regulated by different serine-threonine kinase proteins called cyclin-dependent kinase (Cdk). These proteins regulate the different steps of cell cycle progression by phosphorylating many substrates (i.e., nuclear lamins) [54]. These proteins are regulated by phosphorylation and dephosphorylation. Thus, Cdks can be activated by phosphatases such as CDC25C (cell division cycle 25 homolog C) for CDK1 or kinase like CAK (Cdk activating kinase). The activity of cdks is also regulated by cyclins, which form heterodimers with cdks leading to an activation of Cdks by conformational change $[54,80]$.

Cell cycle is under the control of other factors, implicated in the regulation of cell cycle transition. These regulatory mechanisms form checkpoints where the cell cycle can be stopped after cellular damage in order to allow repair and to maintain cellular integrity or, alternatively, to eliminate mutated and potentially dangerous cells. The INK4 family (p16, p15, p18, and p19) and the Cip/Kip family (p21, p27, and $\mathrm{p} 57)[54,80,81]$ are key regulators of G1/S transition. For example, after DNA damage, p53, a tumor suppressor gene, activates transcription of $\mathrm{p} 21$, which inhibits cyclin E phosphorylation leading to hypophosphorylation of retinoblastoma protein $(\mathrm{pRb})$ [81]. INK4 family inhibits Cdk4 and Cdk6, whereas Cip/Kip family inhibits all Cdks. Retinoblastoma protein needs to be phosphorylated in order to release transcription factor E2F activating genes involved in the S phase-like PCNA (proliferating cell nuclear antigen) [82]. p53 is also important for the regulation of the G2/M transition, which requires activation of the cyclin B-cdk2 complex. This complex accumulates during the previous step of the cell cycle but is inactivated by a phosphorylation at tyrosine 15 and threonine 14 by Wee 1 and Myt 1 . These phosphate groups are removed by the phosphatase CDC25A when cells enter mitosis. In the case of DNA damages, p53 is activated and increases the level of p21 that is directly inhibiting cdk2. Moreover, 14-3-3 protein, a transcriptional target of $\mathrm{p} 53$, leads to a sequestration of cdk2 in the cytoplasm [83]. Other mechanisms involved in the regulation of the $\mathrm{G} 2$ checkpoint or the mitotic spindle checkpoint are reviewed by Stewart et al. [54].

Cancer cells are characterized by deregulation of the cell cycle via alteration of cell cycle controllers (cyclins) and cell cycle regulators (p53) [54], resulting in a perturbation of cell cycle checkpoints.

Currently, there is evidence that prostaglandins produced by COX-2 intervene in tumor cell proliferation as NSAIDs and selective COX-2 inhibitors inhibit proliferation of different cancer cell types expressing COX-2 [30]. NS-398, a COX-2 specific inhibitor, was described to reduce cell proliferation of MC-26 cell line, a highly invasive mouse CRC cell model expressing constitutively COX-2 [8]. This effect was associated with a reduction of cyclin D level, a key protein involved in G1-S transition [54], and PCNA, thus increasing the processivity of DNA polymerase [82]. NS-398 and COX-2 specific inhibitor nabumetone reduced cell proliferation of U937 (acute promonocytic leukemia) and ML1 (human myeloblastic leukemia), thus leading to an accumulation in G0/G1 phase [33]. Interestingly, meloxicam was also able to downregulate PCNA and cyclin A in HepG2 cell line (hepatocellular carcinoma cells), leading to an inhibition of the cell proliferation and an accumulation of the cells in G0/G1 phase of cell cycle [84]. Alternatively, the link between COX-2 and CRC has been demonstrated by the fact that prostaglandin E2 (PGE2) derivating from COX-2-mediated arachidonic acid metabolism increased the proliferation of colorectal cancer cells [85].

The inhibitory effect of NSAIDs on cell proliferation of CRC has been also observed in ovarian cancer. Indeed, treatment of OVCAR-3 tumors xenotransplanted in nu/nu mice (nude mice) with aspirin and piroxicam (NSAIDs) and the selective COX-2 inhibitor meloxicam led to a reduction of tumor growth [86].

It has been estimated that $40 \%$ of breast cancers show an overexpression of COX-2, which is associated with a bad prognosis [5]. Indomethacin (NSAIDs), celecoxib, rofecoxib and nimesulide have been shown to able to inhibit cell proliferation of these cells [5]. Moreover, prostaglandins were able to increase cell proliferation of hormonal-dependent breast cancer by increasing transcription of CYP19 aromatase implicated in estrogen biosynthesis [87].

Several studies revealed that inhibition of COX-2 by celecoxib in Burkitt's lymphoma cell lines RAJI, BjAB, (Epstein-Barr virusnegative), and BL41 led to a reduction of cell proliferation [34]. NS-398 and celecoxib were able to reduce proliferation of pancreatic cancer cell line, Panc- 1 in a dose-dependent manner [88]. Treatment with celecoxib of these cells implanted into nude mice led to a reduction of 


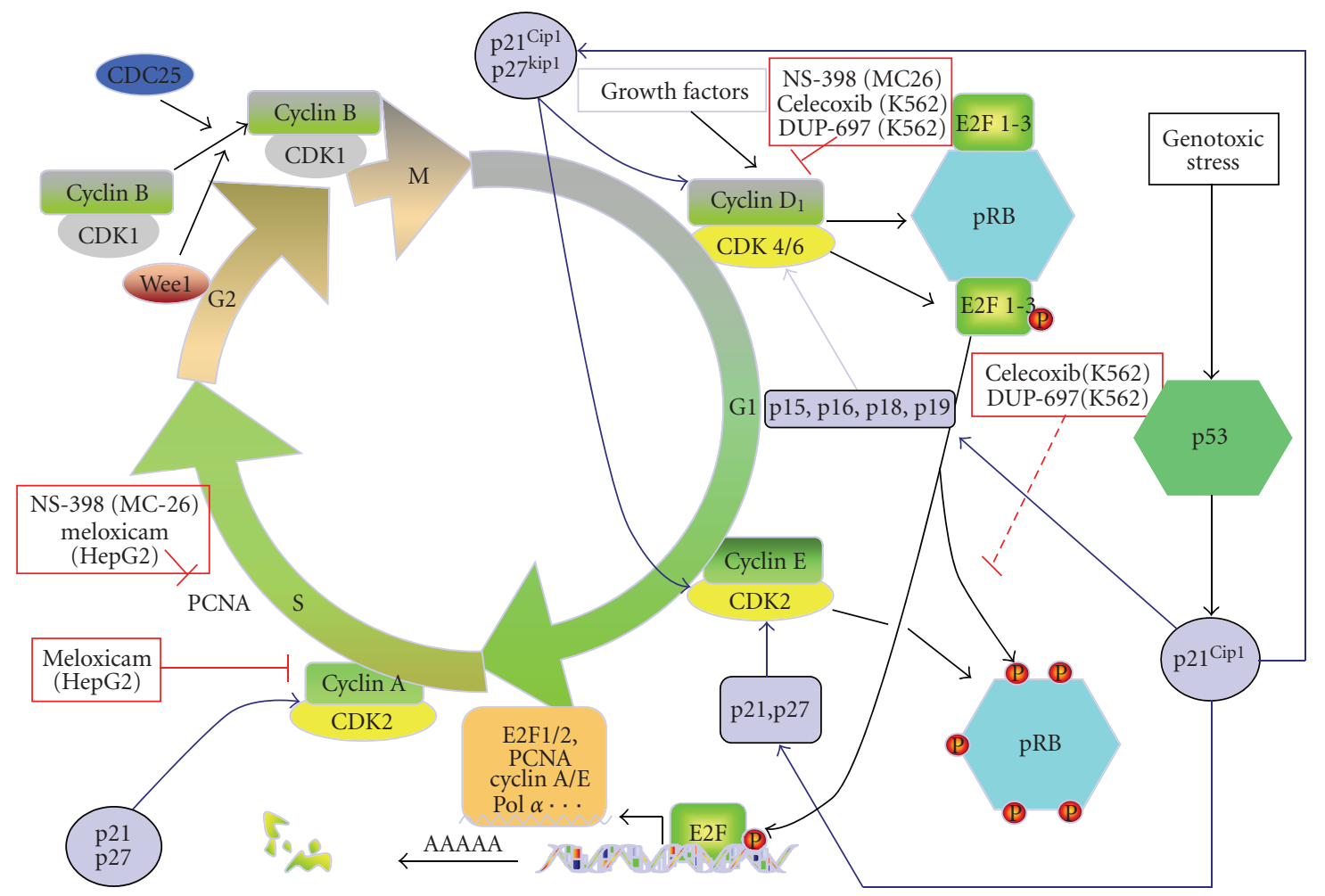

FIGURE 3: Effects of COX-2 inhibitors on cell proliferation. Cell cycle is divided into different steps: G1, S, G2, and M (mitosis). This process is regulated by cyclin proteins, which activate cyclin-dependent kinase (cdk) and phosphatase (i.e., CDC25) or kinase like cyclin-dependent kinase inhibitors such as p16, p15, p18, p19, p21, and p27 [54]. Selective COX-2 inhibitors are able to modulate some cell cycle checkpoints. In this picture, some examples of this link have been shown for different cell types: MC26, colorectal cancer; HepG2, hepatocellular carcinoma; K562, chronic myeloid leukemia. Cdk; cyclin-dependent kinase; pRb, retinoblastoma protein; PCNA, proliferating cell nuclear antigen.

the volume of the tumor [88]. Other studies have shown that celecoxib is able to reduce cell proliferation of the chronic myeloid leukemia (CML) cell line K562, which expresses COX-2 at the mRNA and protein level [89]. This effect was accompanied by an accumulation of cells in G0/G1. Moreover, the inhibition of cell proliferation was correlated to a downregulation of cyclin D1, cyclin E, and $\mathrm{pRb}$ and the upregulation of p16 and p27 [89]. Similar results were found on this cell type with the other selective COX-2 inhibitor DUP-697 [77]. Different effects are recapitulated in Figure 3.

\section{Implication of COX-2 in Cell Death}

5.1. Apoptosis. Apoptosis (type I cell death) is important for the development and maintenance of tissue homeostasis of multicellular organisms [90, 91]. This active form of cell death is characterized by the occurrence of typical cell alterations including plasma membrane blebbing, cell shrinkage, chromatin condensation and nuclear fragmentation, and, finally, formation of apoptotic bodies, which can be phagocyted by macrophages [92]. Deregulation of apoptosis is linked to several pathophysiological disorders, including autoimmune disorders, Alzheimer's disease, and cancer [93].

Two major cascades of intracellular events are commonly involved in mediating apoptosis (Figure 4). The intrinsic pathway, also called the mitochondrial or stress-induced apoptotic pathway, is activated in response to damaging stresses, such as DNA damage. Typical hallmarks of this pathway are mitochondrial outer membrane permeabilization (MOMP), accompanied by a collapse of the mitochondrial membrane potential [51]. These events lead to the release of cytochrome $c$ into the cytosol, which is an indispensable component of the apoptosome, the death complex formed also by APAF-1, and procaspase-9. Once recruited, this protease is cleaved to its activated form (caspase-9) to further activate the executor caspase- 3 and, finally, to finalize the apoptotic program.

Alternatively, the extrinsic, or physiological, apoptotic pathway (Figure 4) can be triggered upon binding of specific ligands to death receptors characterized by the presence of a death effector domain [94]. Ligands include cytokines, such as TNF $\alpha$, tumor necrosis factor-related apoptosisinducing ligand-induced apoptosis (TRAIL), or FAS. After binding, death inducing silencing complex (DISC) is formed. The DISC is composed by the adaptors proteins TRADD (TNF receptor-associated death domain) and FADD (Fasassociated death domain) and is able to recruit and activate pro-caspase- 8 . Finally, caspase- 8 activates caspase- 3 in order to trigger the final steps of apoptosis (Figure 4).

Cross-talks between the two pathways take place. The extrinsic apoptotic pathway can activate the intrinsic 


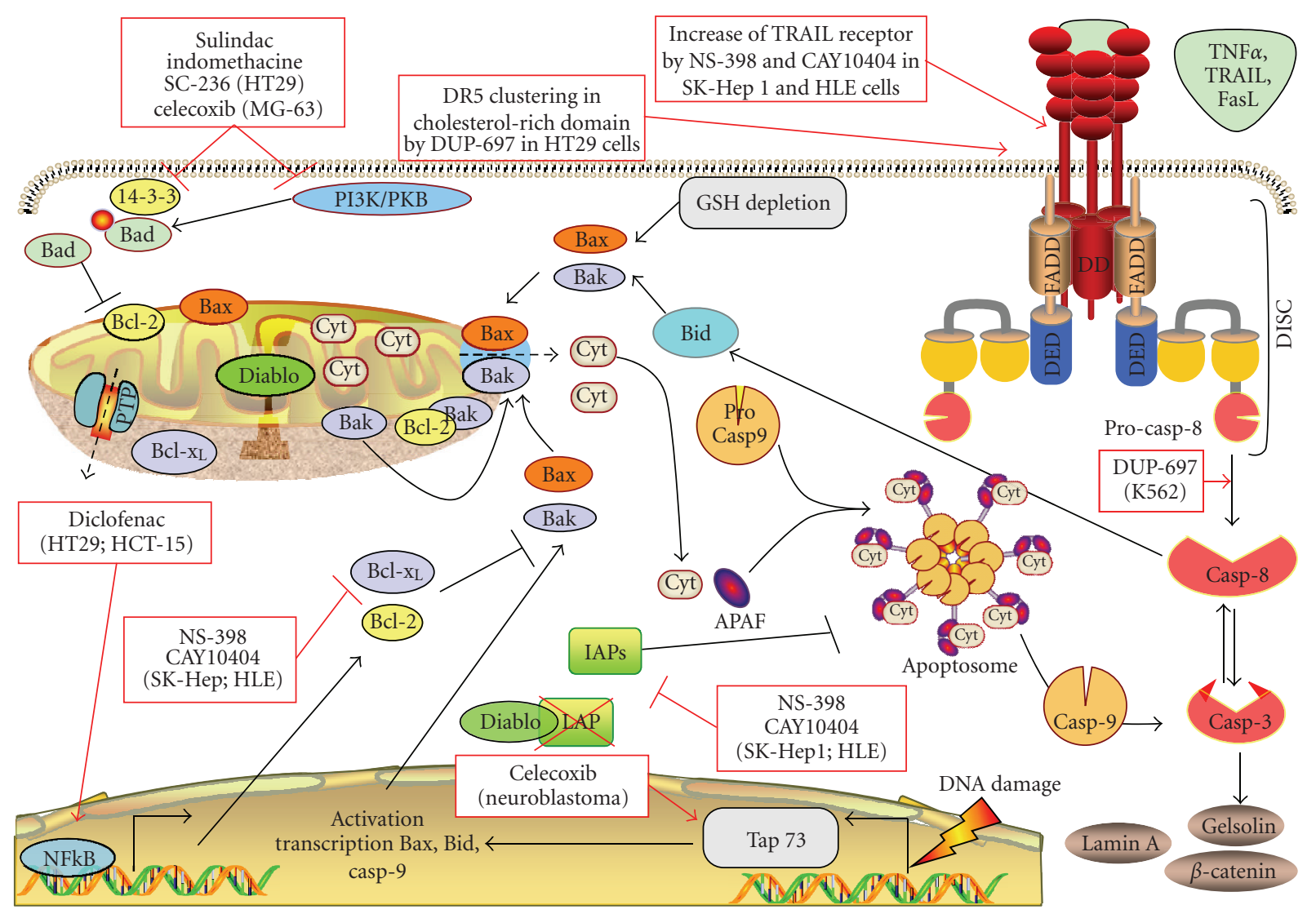

Figure 4: Effects of COX-2 inhibitors on apoptosis. Apoptosis can be mainly mediated by two pathways: the mitochondrial, intrinsic, or stress-induced apoptosis, which is activated in response to damaging stresses and the extrinsic pathway, triggered by the binding of ligands to specific death receptors [51]. COX-2 inhibitors are able to modulate stress-induced apoptosis as well as extrinsic apoptosis in several cell types. In this picture, some examples of these interaction discussed in the text are presented for different cell types: LNCaP, prostate cancer; K562, chronic myeloid leukemia; HT29, colorectal cancer; SK-Hep 1 and HLE, human hepatocarcinoma cells; HepG2, hepatocarcinoma; Be17402, hepatocarcinoma; SMMC-7402, hepatocarcinoma; MG-63, osteosarcoma. Abbreviation: AIF: apoptosis-inducing factor; Bcl-2, B cell lymphoma 2; Bid, Bcl-2 interacting domain; Casp, caspase; Cyt, cytochrome C; DD, death domain; DED, death effector domain; DISC, death-inducing silencing complex; PI3K/PKB, phosphatidyl inositol-3 kinase/protein kinase B; FADD, Fas-associated death domain; GSH, glutathione; PTP, transition permeability pore; TNF, tumor necrosis factor; TRAIL, TNF-related-inducing-apoptosis-ligand.

pathway via truncation of the $\mathrm{BH} 3$-only protein $\mathrm{Bid}(\mathrm{t}$ Bid) by caspase- 8 . $\mathrm{t}$-Bid interacts with mitochondria, by favoring the activation of the proapoptotic Bcl-2 family members Bak and Bax, thus leading to MOMP and caspase9 activation [51, 95] (Figure 4). The intrinsic apoptotic pathway may, in turn, activate caspase- 8 , downstream to caspase-3 [96] (Figure 4). Cross-talks represent an important strategy of amplification loops carried out by dying cells to ensure/potentiate cell death.

5.1.1. Involvement of COX-2 in Intrinsic Apoptosis. When cells are damaged by a variety of chemicals or physical stress (i.e., reactive oxygen species, UV, and ionizing radiation), they undergo apoptosis by triggering the intrinsic apoptotic pathway (Figure 4). This pathway may be associated with a redox disequilibrium, mediated by depletion of glutathione (GSH) $[94,97,98]$, required for the activation and translocation to mitochondria of the Bcl-2 pro-apoptotic member Bax [98], which, in turn, forms complexes (oligomers) mediating MOMP and cytochrome $c$ release. As Bax, Bak may play the same role [99]. In contrast to Bax, Bak is already present at the surface of mitochondria, normally sequestered in its active monomeric form by the $\mathrm{Bcl}-2$ anti-apoptotic members Bcl-xL and Mcl-1 (see Burlacu for a general overview of the Bcl-2 family members modulation involved in Bax/Bak activation [51]).

Apoptosis is regulated in order to maintain tissue homeostasis. This regulation implicates protein-protein interactions, with some of them counteracting apoptosis. In this view, the interaction between $\mathrm{Bcl}-2$ family pro- and antiapoptotic members represents a crucial and delicate step. $\mathrm{Bcl}-2$ is the best described member of this family preventing Bax activation [51]. Bax can form also a complex with the anti-apoptotic protein Bcl-xL [53] and Mcl-1 [14]. Similarly, Bak activity is monitored by the anti-apoptotic members $\mathrm{Bcl}$ $\mathrm{xL}$ and Mcl-1 [51]. The interaction between Bax/Bak and the Bcl-2 family anti-apoptotic members is carefully regulated by the $\mathrm{BH}-3$-only proteins. Another carefully regulated downstream checkpoint of the apoptotic pathway is the activation of caspases. Inhibitor of apoptosis (IAP) family, by directly 
interacting with caspases (i.e., XIAP, survivin [100]) controls and prevents their activity once cleaved. IAPs monitoring function can be, in turn, counteracted by the pro-apoptotic SMAC/DIABLO, a mitochondrial heterodimer, which is released from mitochondria when MOMP is affected [101]. This interaction favors the induction of apoptosis.

Imbalance between cell proliferation and apoptosis observed in cancer can be tightly related to an altered function of pro-apoptotic proteins as well as to an upregulation of anti-apoptotic proteins (i.e., Bcl-2 or IAPs) or a downregulation of tumor suppressor genes (i.e., p53). In addition, the activation of prosurvival pathways (i.e., PI3K/Akt) may be implicated upstream. Inflammation can contribute to this imbalance via cytokines secreted in the tumor microenvironment able to activate survival pathways. For example, TNF $\alpha$ can induce $\mathrm{NF} \kappa \mathrm{B}$, leading to an inhibition of apoptosis [38]. COX-2 seems also to play a role in this process because it is known that COX-2 inhibition is correlated to an increase of apoptosis in several cancer models. NS-398 downregulated Bcl-2 expression in an androgen-sensitive human prostate cancer cell line LNCaP that exhibited a high constitutive level of COX-2 [102]. Similar results have been observed in human colorectal cancer cells (HCA-7 cell line which expresses COX-2) where PGE2 was able to inhibit apoptosis induced by SC58125, a selective COX-2 inhibitor, and increase Bcl-2 expression [46]. Different mechanisms are supposed to explain how COX-2 inhibitors may trigger apoptosis. In a number of studies, COX-2 inhibition was linked to a concomitant increase of intracellular arachidonic acid. In HT-29 human colon adenocarcinoma cell this accumulation led to the induction of apoptosis [103]. The arachidonic acid-induced apoptosis was inhibited by $\mathrm{Bcl}-2$ transfection, indicating a role of arachidonic acid in affecting Bcl-2 intracellular levels [103]. Accumulation of arachidonic acid can affect apoptosis by mediating an increase of pro-apoptotic intracellular ceramides caused by activation of sphingomyelinase $[104,105]$. Sulindac sulphide, a metabolite of sulindac, also activates sphingomyelinase and enhances the ceramide level in the two human colorectal carcinoma cell lines HCT116 and SW480 [106].

COX-2 reduces pro-apoptotic nitric oxide (NO) levels in cancer cells downstream of prostaglandin production [30] (see Brüne et al. [107] for an overview on nitric oxide role in apoptosis). Chang et al. reported that PGE2 prevented apoptosis induced by NGF (nerve growth factor) withdrawal by increasing the level of dynein light chain, an inhibitor of neuronal NO synthase in pheochromocytoma of the rat adrenal medulla PC12 cells, thus leading to decreased intracellular NO levels [108].

More recently, connections between COX-2 inhibitors and p53 family members have been described. For example, celecoxib was shown to able to modulate different isoforms of p73, a p53 family member in neuroblastoma cell lines [109]. p73 encodes many isoforms with different roles. Tap73 is pro-apoptotic and contains a transactivation domain. This isoform is considered as a tumor suppressor gene because it seems to be involved in cell cycle regulation as well as in apoptosis induction $[109,110]$. In contrast, DeltaNp73 is anti-apoptotic and lacks the transactivation domain. DeltaNp73 is overexpressed in neuroblastoma, leading to chemotherapy resistance [109]. It has been shown that celecoxib was able to upregulate Tap73 and downregulate DeltaNp73. These data suggest the use of COX-2 inhibitors as p73 modulators in order to improve efficiency of chemotherapy [110].

The apoptotic effect of COX-2 inhibitors has been also observed for other tumor cell types, such as in the chronic myeloid leukemia model K562 where DUP-697 induced apoptosis by cell cycle arrest and caspase-8 activation [77].

COX-2 inhibitors can also activate prosurvival pathways. The PI3K/Akt pathway is a survival pathway, frequently activated in cancer cells [49]. PI3K produces PIP3 (phosphatidylinositol 3,4,5 triphosphate) that activates PDK1 (pyruvate deshydrogenase kinase). This protein phosphorylates and activates PKB (protein kinase B), which, in turn, is responsible for the phosphorylation of several targets playing a modulator function in apoptosis. An anti-cancer effect of celecoxib due to the inhibition of Akt signaling [111] was observed in a gastric cancer model. Celecoxib triggered also apoptosis in osteosarcoma cells (MG-63) through downregulation of $\mathrm{Bcl}-2$, survivin and $\mathrm{PI} 3 \mathrm{~K}$ (phosphoinositide 3kinase) pathway [112]. Similarly, Hsu et al. [113] found that inhibition of Akt phosphorylation by celecoxib in prostate cancer models (LNCaP and PC3 cell lines which express constitutively COX-2) led to apoptosis, but in this case without affecting Bcl-2 level.

The PI3K pathway is negatively regulated by PTEN (phosphatase and TENsin homolog), which converts PIP3 in PIP2, preventing PKB activation and Bad phosphorylation/sequestration. Thus PTEN is considered as a tumor suppressor gene. It has been shown that NS-398 was able to increase the level of PTEN in human gastric carcinoma cell line MKN45 [114].

One of the PKB targets is Bad, a BH3-only member [51]. The nonphosphorylated form of Bad plays a pro-apoptotic role, by binding $\mathrm{Bcl}-\mathrm{xL}$ or $\mathrm{Bcl}-2$ and, thus, preventing their interactions with Bak and Bax. The activation of PI3K/Akt pathway may lead to the phosphorylation of Bad, which is consequently sequestrated in the cytoplasm by 14-33 protein and, in this way, inhibited in its pro-apoptotic function [51]. It has been reported that sulindac sulphone, indomethacine, and SC-236 were able to induce apoptosis via Bad activation, by inhibiting 14-3-3 expression in a dose- and time-dependent manner in HT-29 cells [115]. This effect was tightly related to $\operatorname{PPAR} \delta$. It is known, indeed, that 14-3-3 protein contains PPRE recognized and bound by $\operatorname{PPAR} \delta$ [115]. COX-2 can mediate the synthesis of prostaglandin I2, which can bind and activate $\operatorname{PPAR} \delta$ [41]. Thus, it has been suggested that the inhibition of COX-2, leading to a decrease of PGI2, impaired PPAR $\delta$ activation, which, in turn, was responsible for a downregulation of 14-3-3 protein, thus allowing Bad to play its pro-apoptotic functions [115].

$\mathrm{NF} \kappa \mathrm{B}$ is a most important transcription factor involved in survival by enhancing transcription of anti-apoptotic proteins such as $\mathrm{Bcl}-2[14,15]$. Sulindac inhibits $\mathrm{NF} \kappa \mathrm{B}$ in two colon cancer cell lines (human colon adenocarcinoma 
HCT-15 and HT29 cell lines) [116]. Similar results were obtained with diclofenac, which was able to inhibit nuclear accumulation of $\mathrm{NF} \kappa \mathrm{B}$ [117]. In the same study, PGE2 was demonstrated to increase the transcriptional activity of $\mathrm{NF} \kappa \mathrm{B}$ p65/p50 dimer in CACO-2 cells (human epithelial colorectal adenocarcinoma cells), transfected with a luciferase construct containing $\mathrm{NF} \kappa \mathrm{B}$ response elements [117].

It is known that activation of prostaglandin receptors induces an increased cAMP level which in turn can activate protein kinase A (PKA) [58]. Studies have suggested that PKA, like PKB, phosphorylates Bad [118], leading to its sequestration and inhibition of apoptosis. Some of the proor anti-apoptotic mediators affected by COX-2 inhibitors are schematized in Figure 4.

\subsubsection{Implication of COX-2 in Extrinsic Apoptotic Cell Signal-} ing Mechanisms. Studies reported that COX-2 inhibitors are also associated with a sensitization of tumor cells to extrinsic apoptosis. Thus, DUP-697 sensitized HT29 colon cancer cell line to TRAIL-induced apoptosis. This effect was due to an accumulation of arachidonic acid inside the cells, which activates sphingomyelinase, triggering a clustering of death receptor (DR) 5 receptors in ceramide and cholesterolrich domains [119]. Alternatively, the expression of COX2 has been frequently associated with a modulation of the expression of death receptors, thus leading to an upstream control of the extrinsic apoptotic pathway. Tang et al. [120] showed that COX-2 overexpression in human colon cancers cells led to an inhibition of DR5 expression and a resistance to TRAIL-induced apoptosis. Accordingly, COX-2 specific inhibitors, NS-398 and CAY10404, are sensitizing human hepatocarcinoma cells (SK-Hep1 and HLE) to TRAILinduced apoptosis. This effect was due to an upregulation of TRAIL receptors (TRAIL R2/DR5 and TRAIL-R1/DR4), together with an ability of the compounds to induce a downregulation of the anti-apoptotic proteins survivin (IAP) and Bcl-xL [121]. In hepatocellular carcinoma models (HepG2, Bel7402, and SMMC-7402), Li et al. [84] showed that COX2 inhibition with meloxicam led to an upregulation of Fasmediated apoptosis. In vivo studies performed on transgenic mice constitutively expressing human COX-2 confirmed an increased resistance to Fas-induced apoptosis in liver, as shown by the preservation of liver architecture in COX2-expressing mice compared to wild type [122]. Similarly, another study performed on human extrahepatic bile duct carcinoma cell line showed that COX-2 induction led to the inhibition of Fas-induced apoptosis, whereas the inhibition of COX-2 with NS-398 in cytokine-treated cells exacerbated apoptosis induced by $\mathrm{CH}-11$, an agonist of Fas receptor [123].

AKT pro-survival pathway may play a role also in the modulation of extrinsic apoptosis. The human gastric carcinoma cell line MKN45, which expresses COX-2, was sensitized to Fas-induced apoptosis by NS-398. The COX2 inhibitor, indeed, was able to increase the level of PTEN, leading to a decrease of Akt phosphorylation and activation of Bad [114]. Some effects of COX-2 inhibitors on extrinsic apoptosis are summarized in Figure 4.
Altogether, these results encourage the perspective that COX-2 inhibitors could be used in future as a therapeutic strategy to sensitize tumor cells to apoptosis induced by physiological stimuli.

\subsection{Involvement of COX-2 in Other Types of Cell Death}

5.2.1. Anoikis. Anoikis is a form of apoptosis mediated by the loss of cell anchorage. This pathway plays a fundamental role during development and maintenance of tissue homeostasis by killing damaged cells or detached cells in order to maintain tissue architecture. For example, the inner endodermal cells undergo anoikis after the loss of anchorage to the matrix during development [124]. It is known also that intestinal epithelial cells loose anchorage when located at the luminal surface, leading to anoikis [42]. As a form of apoptosis, anoikis is dependent on caspase activation and cytochrome $c$ release by mitochondria and is regulated by Bcl-2 family members [42].

It has been shown that anoikis is prevented in cancer cells, thus favoring tumor progression with the formation of metastasis [42]. Accordingly, modulation of anoikis is considered a promising target for anti-cancer strategies.

Cell anchorage is due to cell-cell and cell-matrix interactions. Cell-cell interactions are mainly mediated by integrins which are transmembrane receptors located at the cell surface and composed of alpha and beta chains [125]. Many intracellular signals can act downstream to integrins, which, correctly switched on, can ensure cell survival. Some of them are mediated by kinases such as Focal-adhesion-kinase (Fak) or integrin-linked kinase (ILK) [42]. Fak is phosphorylated upon integrin adhesion, leading to activation of other signaling pathways like PI3K, MAPK. ILK is a serine/threonine kinase that directly phosphorylates PKB.

Together with cell-cell and cell-matrix interactions, paracrine factors could be important for the regulation of anoikis. It has been shown that E-cadherin (epithelial cadherin) can activate COX-2 [23]. It is possible that prostaglandins produced by COX-2, which act in an autocrine and a paracrine manner, favor cell survival. A study from Joseph et al. [126] showed that PGE2 inhibited anoikis in IEC-18 cells (rat intestine ileum cells). This effect was suggested to be due to cAMP signaling because prostaglandin E2 receptors are coupled to adenylate cyclase, which converts AMP to cAMP [126].

Other studies demonstrated that COX-2 inhibits anoikis via activation of PI3K/Akt pathway, as the case of a human bladder cancer cell line expressing COX-2 [40]. A link between COX-2 and anoikis has been described, furthermore, in uterine endometrial carcinoma [127]. COX-2 is over-expressed in this type of cancer and this is associated with tumor aggressiveness. In addition, a recent report based on HEC-1B and RL95-2 (two human endometrial cancer cell lines) showed that the treatment of these cells with hepatocyte growth factor (HGF) led to an up-regulation of COX-2. Hepatocyte growth factor interacts with its tyrosine kinase receptor c-Met. This interaction is responsible for tumor progression. Overexpression of HGF/c-Met has been described in different tumors such as breast cancer [128] 
as well as head and neck cancer [129], also in endometrial carcinoma [130]. It has been demonstrated that HGF inhibited anoikis and treatment of HEC-1B and RL95-2 cells with the COX-2 selective inhibitor meloxicam prevented HGF-mediated anoikis resistance [127]. Similar results were obtained in head and neck squamous cell carcinoma [131].

Altogether these data suggest that COX-2 may be implicated in the inhibition of anoikis and that COX-2 inhibitors may play a role in inhibiting tumor progression (metastasis), by sensitizing tumor cell to anoikis.

5.2.2. Autophagy. Autophagy is a process triggering cells to degrade intracellular constituents, ranging from proteins up to entire organelles. It represents an important process ensuring the turnover of long-lived cellular components, which can be activated also by stress conditions like nutrient starvation in order to avoid cell death. The process starts with the formation of doubled membrane-bound vacuoles corresponding to autophagosomes that entrap parts of the cytoplasm or organelles (i.e., mitochondria). Then, these structures are fused with lysosomes (autolysosomes), thus leading to the degradation of the intracellular parts previously enclosed. Together with apoptosis, when exacerbated, autophagy contributes to the modulation of homeostasis, by eliminating damaged and potentially dangerous cells (type II cell death) [132]. However, the relationship between apoptosis and autophagy is currently still poorly understood [132] because in some cases autophagy permits an adaptation of the cells to stress (i.e., nutrient starvation), thus counteracting apoptosis, whereas, in other cases, autophagy is a process triggering downstream apoptosis [132]. Indeed, similar stimuli can induce both apoptosis or autophagy [132].

This process is implicated in pathologies such as Alzheimer's disease and cancer, suggesting a promising field in therapy. By considering that COX-2 is supposed to play a role in apoptosis and a link between apoptosis and autophagy exists, it is conceivable that COX-2 plays a role also in this process. Currently, not many studies aimed at investigating a possible link between COX-2 and autophagy have been published. Nevertheless, one study revealed that sulindac sulphide (NSAIDs) induced apoptosis of the colon cancer HT29 cell line. This effect was increased by treatment of the cells with 3 methyl-adenine, a well-known inhibitor of autophagy [133]. Moreover, the extent of apoptosis in Q204L cells (a clone of HT-29 cells in which 3 methyladenine-sensitive autophagic sequestration is impaired) was less than in HT29. These data suggest that autophagy can delay sulindac sulphide-induced apoptosis [133].

\section{COX-2 Inhibitors in Cancer Therapy}

Despite the latest progress in cancer research and the different strategies to kill cancer cells, several tumors are resistant to conventional therapeutics treatment (i.e., radiotherapy, chemotherapy, and photodynamic therapy).

COX-2 inhibitors play an important role in cancer prevention. Indeed, the chronic intake of NSAIDs is able to consistently reduce the appearance and incidence of many types of cancer as described in Familial Adenomatous
Polyposis (for celecoxib) $[134,135]$ and also in breast cancer [136]. This property of COX-2 inhibitors could be useful for patients with a high risk to develop cancer such as people with Li-Fraumeni syndrome, for example [137]. The fact that many reports in literature suggest that COX-2 inhibitors are responsible for an inhibition of cell proliferation and apoptosis induction in a number of different cancer cell models prompts to consider a possible use of COX-2 inhibitors in future therapeutical protocols, administered alone as well as in combination with anti-cancer clinical protocols in order to improve tumor cell death.

6.1. COX-2 Inhibitors in Combination with Radiotherapy. Radiation therapy is a common treatment used for the treatment of solid tumors, such as breast, prostate, colorectal, and lung cancers. It is known that the anti-cancer properties of ionizing radiation are due to pleiotropic mechanisms. Radiation leads to the formation of DNA doubled-strand breaks in proliferating cells, which triggers the activation of DNA damage pathways (i.e., p53), followed by the induction of apoptosis [36]. The importance of Bcl-2 family members during apoptosis [51] suggests that prosurvival proteins (i.e., $\mathrm{Bcl}-2, \mathrm{Bcl}-\mathrm{xL}$ ) play an important role in radioprotection of tumor cells. The NFkB pathway seems to be implicated, being required in regulating expression of the anti-apoptotic $\mathrm{Bcl}-2$ family members like Bcl-xL [36]. Moreover, it is well established that $\mathrm{NF} \kappa \mathrm{B}$ regulates the level of COX-2, suggesting that COX-2 may play a role in radiotherapy resistance [21]. Similarly, nimesulide could increase radiation efficiency in nonsmall cell lung cancer in vivo (nude mice) and in vitro (A549 cell line) as shown by Grimes et al. [138]. This effect was due to a down-regulation of MnSOD (superoxide dismutase containing manganese $(\mathrm{Mn})$ and localized in mitochondria), a primary antioxidant protein and survivin, an anti-apoptotic protein (IAPS family member). These two proteins are regulated by $\mathrm{NF} \kappa \mathrm{B}$. It is well known that during radiation therapy $\mathrm{NF} \kappa \mathrm{B}$ can be upregulated due to reactive oxygen species release and inflammation (i.e., PGE2). This report suggests that nimesulide may act on $\mathrm{NF} \kappa \mathrm{B}$ to inhibit MnSOD and survivin.

Melanoma is known to be very resistant to conventional radiotherapy and chemotherapy. Irradiation of two melanoma cell lines WM35 and LU1205 in the presence of NS-398, a selective COX-2 inhibitor, strongly exacerbated the G2/M arrest as well as the induction in apoptosis. Accordingly, the down-regulation of COX-2 by RNA interference in these cell lines was followed by an upregulation of p53 and G2/M arrest [36], thus confirming that the effect of NS-398 is due to its role on COX-2 inhibition.

Other studies have shown that the radiosensitivity of PC3 (human prostate carcinoma cells) and Hela (human cervical carcinoma cells) was enhanced after silencing of COX-2 by siRNA. NS-398 was able to increase radiosensitivity of PC3 cells expressing COX-2, but not in PC3 silenced for COX-2. In contrast, NS-398 enhanced radiosensitivity of Hela cells, irrespective to the level of COX-2 [37].

However, combination of COX-2 inhibitors with radiation therapy can also lead to a reduction of efficiency of the radiotherapy. In one report, it has been shown that the 
selective COX-2 inhibitor nimesulide decreased radiation efficiency of two head-and-neck cancer cells lines (SCC9 and SCC25) which are COX-2 positive [139]. This suggests that the sensitization of tumor cells to radiation might be strongly dependent on tumor cell type.

6.2. COX-2 Inhibitors in Combination with Chemotherapy. Many types of cancer are treated with chemotherapeutic agents leading to inhibition of cell proliferation or induction of apoptosis [140].

One of the major causes of chemotherapy failure is the survival and/or development of multidrug resistant cancer cells. This resistance is mediated by many mechanisms including over-expression of proteins involved in inhibition of apoptosis (i.e, Bcl-2), leading to insensitivity of tumor cells to apoptotic stimuli; an up-regulation of DNA repair; alteration of the target; up-regulation of detoxification enzymes (i.e., Glutathione S-transferases); and extrusion of chemotherapeutic drugs by overexpression of ATP-binding cassette family proteins, such as MRP (multidrug resistantassociated protein) BCRP (breast cancer resistance protein or mitoxantrone resistance protein) because these proteins regulate absorption, distribution, and excretion of various pharmacologic compounds [141]. Consequently, the chemotherapeutic agents are immediately extruded from the cells. P-gp (P-glycoprotein) is one of the best-understood mechanisms leading to multidrug resistance (MDR). Tremendous efforts have been made to find solutions to overcome MDR. Recently, COX-2 inhibitors showed an ability to sensitize tumor cells to chemotherapeutic agents in several models and also in clinical assays. Colorectal cancers are particularly affected by chemoresistance. One study revealed that the COXs inhibitors naproxen and indomethacin heptyl ester were able to downregulate P-glycoprotein in human colorectal CACO-2 cell line. [39]. Indomethacin inhibited the activity of the protein and affected COX-2 mRNA and protein level [39]. Another study showed that meloxicam was able to downregulate MDR1 in HL60 (a human promyelocytic leukemia) cell line as well as in acute myeloid leukemic blasts [142]. The regulation of MDR1 by COX-2 has been also suggested in another study [143] in which it was reported that transfection of COX-2 cDNA with adenovirus in renal rat mesangial cells led to an upregulation of MDR1 gene. The combination of COX-2 inhibitors with chemotherapy was also assayed in a study in which the sensitivity of a human gastric cancer cell line MKN45 to cisplatin (alkylating agent) resulted increased by COX-2 downregulation with siRNA [35], suggesting a possible therapeutic application of this combination. Similarly, the sensitivity to cisplatin was increased by celecoxib in a human osteosarcoma cell line (MG-63) and this effect was linked to a down-regulation of anti-apoptotic proteins survivin, Bcl-2, and an inhibition of the survival pathway PI3K/Akt [112]. It was also reported that B-CLL (B chronic lymphoid leukemia) overexpressed COX-2 and the combination of NS398 with chlorambucil, an alkylating agent, increased the level of apoptosis in BCLL blasts coming from patients [32]. Moreover, several lymphoma cell lines overexpressed COX-2, such as RAJI, $\mathrm{BJAB}, \mathrm{BL} 41$ and treatment of these cells with celecoxib led to a decrease of cell proliferation in a dose-dependent manner [34].

NS-398 was able to increase the cytotoxicity of gemcitabine, an analog of the antimetabolite nucleoside deoxycytidine, used for treatment of nonsmall cell lung carcinoma, in A549ACA cell line (lung adenocarcinoma cell line) by enhancing apoptosis [144]. The combination of NS-398 and gemcitabine is also associated with an inhibition of cell proliferation with an accumulation of the cells in G0/G1 phase of cell cycle and an increase of p21 [144].

All of these data suggest that COX-2 is implicated in anti-apoptotic and MDR pathways and that selective COX-2 inhibitors could be used to improve chemotherapy efficiency.

\subsection{COX-2 Inhibitors in Combination with Photodynamic}

Therapy. An alternative therapeutic approach to treat cancers is photodynamic therapy. This procedure is particularly used for such solid tumors including skin, bladder, and head and neck cancers in addition to other diseases like age-related macular degeneration and psoriasis [145]. The treatment consists in the administration of a photosensitizer, a molecule that selectively accumulates in tumors and is activated by light $(600-850 \mathrm{~nm})$. The photosensitizers may accumulate in different compartments of tumor cells like mitochondria (i.e., porphycene monomer), nucleus, lysosomes (i.e., lysyl chlorin p6), and plasma membrane (i.e., monocationic porphyrin like Photofrin). Then, the photosensitizer is excited with a laser from a single state to a triplet state. The triplet-state photosensitizer is implicated in two oxygen-dependent reactions. In the first one, the triplet can react with cell membrane or molecules, leading to radical formation, which in combination with oxygen produce oxygenated products, cytotoxic for the cells [146, 147]. In the second reaction, the triplet-state photosensitizer can transfer its energy directly to oxygen in order to produce singlet oxygen $\left({ }^{1} 02\right)$, which is known to be a very highly reactive oxygen species and is implicated in cell damage. Therefore, this therapy leads to tumor destruction due to cell death occurring via apoptosis and necrosis. Vasculature damages and activation of immune response are two important effects implicated in tumor ablation.

Some parameters affect PDT efficiency, such as the distribution of the photosensitizer, photobleaching, hypoxia/anoxia, and the vascularization of the tumor [146]. The main reason of failure of this therapeutic approach is linked to an up-regulation of angiogenic and inflammatory factors in the tumor microenvironment that strongly reduces the PTD efficiency with a consequent tumor relapse. The link between inflammation and survival pathway activation, cell proliferation, and angiogenesis is well known and contributes to tumor progression $[3,6]$. It has been shown that PDT leads to an increase of TNF $\alpha$, IL1 $\beta$, PGE2, VEGF (vascular endothelial growth factor), and MMP9 (matrix metalloproteinase 9) [147]. These molecules can counteract tumor responses to PTD by promoting cell proliferation and cell survival [38]. Interestingly, it has been demonstrated that COX-2 is upregulated during PDT treatment in different cancer models. As for radiotherapy and chemotherapy, 
this suggests COX-2 as a possible target to increase PDT efficiency.

Indeed, celecoxib has been proved to affect the Photofrininduced PDT in in vitro and in vivo studies performed on a mouse mammary carcinoma BA cell line [148]. In vitro, celecoxib and NS-398 increase PDT-induced apoptosis. These results were correlated with caspase- 3 and PARP cleavage and $\mathrm{Bcl}-2$ degradation. In vivo, the photosensitization by COX-2 inhibitors was not due to apoptosis exacerbation. Interestingly, celecoxib and NS-398 decrease PDT-induced apoptosis but were also able to decrease the level of angiogenic factors such as TNF $\alpha$, IL1 $\beta$, PGE2, VEGF, and MMP9 [148].

Upon chlorin-induced PDT, COX-2 was found up-regulated 25-fold in mouse mammary carcinoma RIF cells [149]. This up-regulation was associated with an increase of PGE2 level in the tumor microenvironment. When RIF cells were transplanted in $\mathrm{CH} 3 / \mathrm{HeJ}$ mice, for in vivo studies, PDT similarly induced an increase of COX-2 and PGE2. These effects were prevented by NS-398. Here, it was demonstrated that PDT induced vascular endothelial growth factor expression (VEGF) and this increase was attenuated by treating mice with NS-398, meaning that COX-2 might play a role also in angiogenesis. In consequence of these effects, the combination of COX-2 inhibitors with PDT resulted in an increased efficiency of tumor treatment.

Possible correlation between COX-2 level and resistance to PDT has been also investigated in Hela (human cervix carcinoma cells) and T24 (human transitional cell carcinoma of the urinary bladder) cells [150]. It has been reported that in PDT induced by hypericin, a natural photosensitizer which accumulates in endoplasmic reticulum and Golgi apparatus, an increase of PGE2 levels occurred. Hypericin induces apoptosis by triggering the release of cytochrome $c$ after light excitation through a process requiring the activation of p38 MAPK, which it is known to induce an up-regulation of COX-2 $[23,151]$. The increase in PGE2 levels was prevented by the use of a p38 MAPK inhibitor (PD169316). Moreover, the impairment of p38 MAPK was associated with an increase in the susceptibility of tumor cells to PDT. However, COX-2 inhibitors did not lead to the same effect, meaning that COX-2 was not involved in PDT resistance in this model.

In contrast to the study of Ferrario et al. [148, 149], a report from Makowski et al. [152] has revealed that rofecoxib, NS-398, and nimesulide were unable to potentiate PDT in C-26 cells (poorly differentiated colon adenocarcinoma cell line) in vitro. However, chronic exposition of mice bearing C-26 cells to nimesulide potentiated PDT. These data suggest that COX-2 inhibitors may indirectly potentiate PDT.

It is known that vasculature damages are important for PDT efficiency and that COX-2 inhibitors act as antiangiogenic factors [153]. It has been hypothesized that these antiangiogenic effects could be responsible for the antitumor effect.

Currently, the link between COX-2 and PDT efficiency is not well characterized. Some studies have revealed an improvement of efficiency with COX-2 inhibitors whereas other reports have demonstrated no direct effects. In any case, this effect may be cell-type dependent as for chemotherapy or radiotherapy.

\section{Inhibition of COX-2 Expression by Natural Compounds}

Synthetic cyclooxygenase-2 inhibitors hold promise for cancer chemoprevention; however, recent toxicity problems suggest that new strategies are needed. Natural compounds with the potential to inhibit key cell signaling pathways including COX-2 gained much attention over the last regarding years whether they are used alone or in combination with existing chemotherapeutic agents.

Recently, Bhui et al. demonstrated that Bromelain, a pharmacologically active compound present in pineapple (Ananas cosmosus), leads to a marked inhibition of COX-2 expression and inactivation of $\mathrm{NF} \kappa \mathrm{B}$. Bromelain treatment induces up-regulation of p53 and Bax and subsequent activation of caspase- 3 and caspase- 9 with a decrease in Bcl-2 expression [154]. Furthermore bromelain induces apoptosisrelated proteins along with inhibition of $\mathrm{NF} \kappa \mathrm{B}$-driven $\mathrm{COX}$ 2 expression by blocking the MAPK and Akt/protein kinase B signaling in DMBA-TPA-induced mouse skin tumors [155].

Curcumin, a naturally occurring polyphenol from Curcuma longa, was described to act as an antiinflammatory and antiproliferative agent by causing downregulation of COX-2 in cervical cancer. Curcumin-mediated apoptosis in these cells is initiated by up-regulation of pro-apoptotic Bax, AIF, release of cytochrome $c$, and downregulation of anti-apoptotic Bcl-2, Bcl-xL in HeLa and SiHa cell lines. This onset of apoptosis was accompanied by an increase in caspase- 3 and -9 activity, suggesting the role of mitochondria in curcumin-mediated apoptotic cell death as described by M. Singh and N. Singh [156]. Marín et al., furthermore, concluded that curcumin inhibits $\mathrm{NF} \kappa \mathrm{B}$ activity as well as the expression of its downstream target genes, and also selectively induces apoptosis of melanoma cells but not normal melanocytes [157]. In addition, curcumin-induced apoptosis was also associated with the activation of caspase- 3 and caspase- 9 , and the degradation of PARP. Curcumin decreased the expression levels of COX-2 mRNA and protein without causing significant changes in COX-1 levels, which was correlated with the inhibition of prostaglandin $\mathrm{E}(2)$ synthesis [158]. In BV-2 microglial cells, curcumin and analogs were shown to inhibit LPS-induced COX-2 expression; analogs identified as more potent than curcumin in the screening assay were also more potent than curcumin in preventing COX-2 expression [159].

Coumarin (1,2-benzopyrone) is a naturally occurring fragrant compound found in numerous plants and spices. Results obtained with human nonsmall cell lung cancer A549 cells suggest that downregulation of $\mathrm{Bcl}-\mathrm{xL}, \mathrm{COX}-2$, and MAP kinase pathway and up-regulation of p53, Akt, and $\mathrm{NF} \kappa \mathrm{B}$ pathway are involved in the underlying molecular mechanism of apoptosis induction as suggested by Goel et al. [160].

Suh et al. concluded that the plant flavonoid fisetin induces apoptosis and suppresses the growth of colon cancer cells 


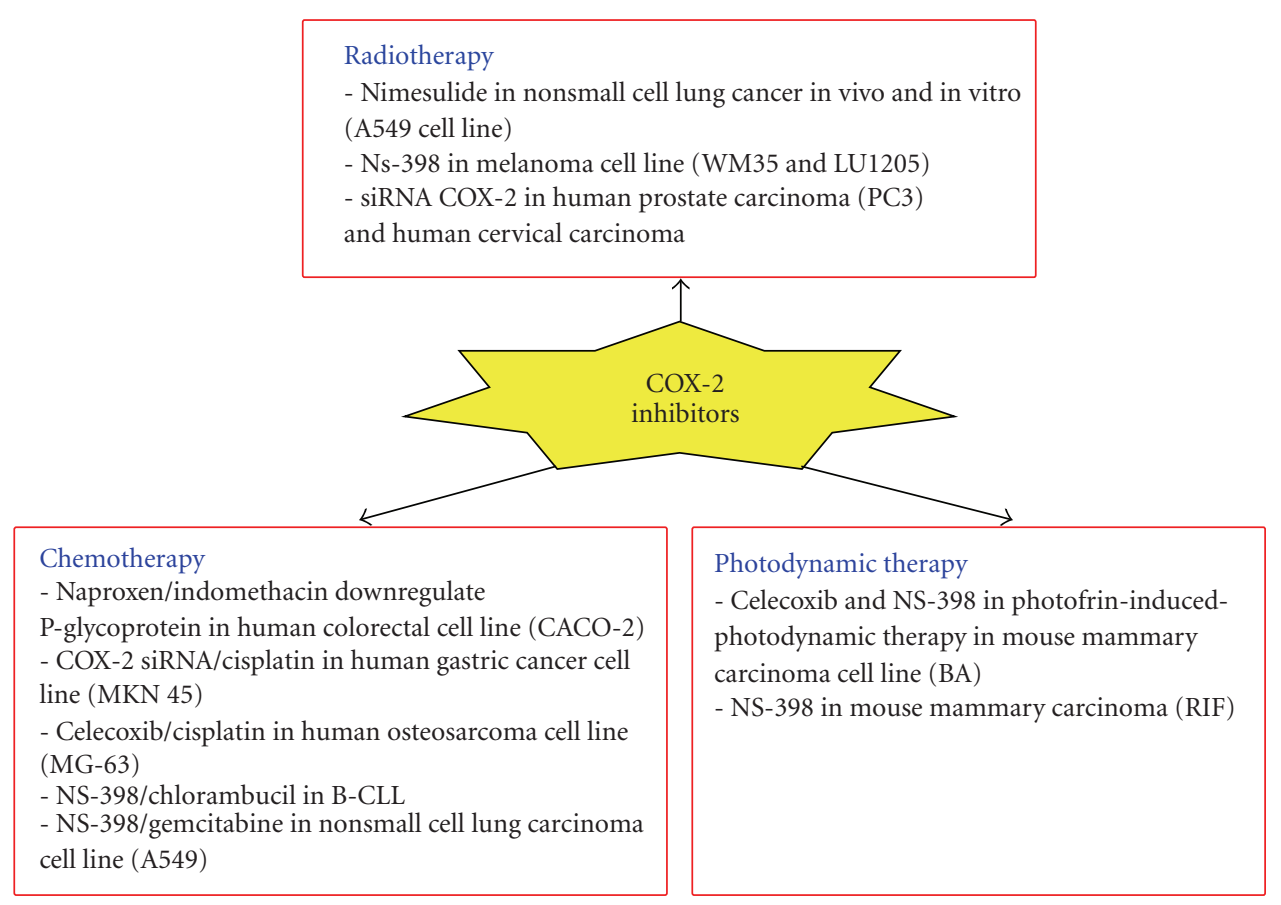

Figure 5: COX-2 inhibition in cancer therapy.

by inhibition of COX-2- and Wnt/EGFR/NF $\kappa$ B-signaling pathways [161].

Sulforaphane (SFN) is a biologically active compound extracted from cruciferous vegetables, and presents potent anti-cancer and anti-inflammatory activities by suppression of NFkB-dependent genes involved in anti-apoptotic signaling (IAP-1, IAP-2, XIAP, Bcl-2, and Bcl-xL), cell proliferation (c-Myc, COX-2, and cyclin D1), and metastasis (VEGF and MMP-9) as published by Moon et al. [162].

Nontoxic apigenin can suppress anti-apoptotic pathways involving $\mathrm{NF} \kappa \mathrm{B}$ activation including cFLIP and COX-2 expression as demonstrated by $\mathrm{Xu}$ et al. [88]. According to Nam et al., DA-6034, a synthetic derivative of flavonoid Eupatilin, strongly enhanced apoptosis and inhibited the expression of COX-2 and phospho-IKKalpha in inflammation-related colon cancer models [163].

EGCG from green tea was described to attenuate the $\mathrm{AR}$, to downregulate IGF-1, to modulate COX-2 expression, and to decrease MAPK signaling leading to the reduction in cell proliferation and induction of apoptosis in prostate cancer without toxicity [164]. Interestingly, combination of EGCG and COX-2 inhibitor NS-398 enhanced cell growth inhibition, apoptosis induction, expression of Bax, procaspase- 6 , and pro-caspase- 9 , and PARP cleavage, inhibition of PPAR gamma, and inhibition of $\mathrm{NF} \kappa \mathrm{B}$ compared with the additive effects of the two agents alone, suggesting a possible synergism. In vivo, combination treatment with green tea polyphenols and COX-2 inhibitor celecoxib resulted in enhanced tumor growth inhibition, lowering of prostatespecific antigen levels, lowering of IGF-I levels, and circulating levels of serum IGF-1 binding protein-3 compared with results of single-agent treatment. Accordingly, Adhami et al. postulate the efficiency of synergistic and/or additive effects of combinatorial chemopreventive agents and further underscore the need for rational design of human clinical trials involving such natural compounds [165].

Pandey et al. published that butein inhibited the expression of the $\mathrm{NF} \kappa \mathrm{B}$-regulated gene products involved in antiapoptosis (IAP2, Bcl-2, and Bcl-xL), proliferation (cyclin D1 and $\mathrm{c}-\mathrm{Myc}$ ), and invasion (COX-2 and MMP-9). Suppression of these gene products correlated with enhancement of the apoptosis induced by TNF and chemotherapeutic agents, and inhibition of cytokine-induced cellular invasion. This group clearly demonstrates that antitumor and anti-inflammatory activities assigned to butein may be mediated in part through the direct inhibition of IKK, leading to the suppression of the $\mathrm{NF} \kappa \mathrm{B}$ activation pathway [166].

Hostanska et al. used human colon COX-2-positive HT 29 and COX-2-negative HCT 116 or lung COX-2 proficient A 549 and low COX-2 expressing SW2 cells and showed that willow bark extract BNO 1455 and its fractions inhibit the cell growth and promote apoptosis in human colon and lung cancer cell lines irrespective of their COX selectivity [167].

\section{COX-2 Independent Effects}

It is currently well known that several selective COX-2 inhibitors inhibit cell proliferation and induce apoptosis independently of COX-2. Celecoxib is particularly known to have these COX-2-independent effects, which were reviewed by Grosch et al. [68]. Indeed, celecoxib was able to directly bind and inhibit PKB/Akt, which plays an important role in cell proliferation and in apoptosis. Concerning cell cycle, $\mathrm{PKB}$ is able to phosphorylate cdk inhibitors, such as p21 and p27, leading to PCNA activation $[168,169]$. Furthermore, $\mathrm{PKB}$ can also activate several cyclin-cdk complexes and 
induce E2F factor in some cases [68], stimulating cell proliferation. Besides, PKB inhibits apoptosis, by phosphorylating the pro-apoptotic protein Bad and by inhibiting caspase- 9 cleavage [51].

The COX-2-independent effects concern also the extrinsic apoptotic pathway. Indeed, we discussed that selective COX-2 inhibitors, such as NS-398, celecoxib, and meloxicam, are able to modulate the sensitivity of several tumor cells to Fas- and TRAIL-induced apoptosis. It has been discussed that this modulation could be due to COX-2independent effects. In fact, NS-398 and nimesulide were able to promote TNF and TRAIL-induced apoptosis of D98 and H21 Hela cell lines [170]. In D98, COX-2 is inactive. Moreover, prostaglandin E2 readdition was not able to revert the sensitization effect. In the same report, it has been shown that NS-398 was able to promote apoptosis induced by TNF in MCF-7 cell line (human breast adenocarcinoma cells), which again does not express COX-2 [170].

A report from Ryan et al. [171] demonstrated that SC58125 and CAY10404, two selective COX-2 inhibitors, were able to decrease intracellular content of GSH in malignant human B-cells. This effect was accompanied by an increase of reactive oxygen species production. Indeed, GSH is the most important intracellular nonprotein thiol antioxidant defense against free radicals, meaning that it protects the cells from cellular damages. The GSH depletion was correlated in this study with a reduced survival for these cells.

The fact that many studies imply an association between COX-2 inhibition and apoptosis induction or cell proliferation inhibition, without assessing whether COX-2 activity is effectively decreased, suggests caution in the interpretation of the data. This is confirmed by the observation that different COX-2 inhibitors may trigger apoptosis in the same cancer cell model by modulating different mechanisms. For example, celecoxib [113] induced apoptosis by an inhibition of Akt phosphorylation in prostate cancer cells COX-2positive $\mathrm{LNCaP}$ without affecting $\mathrm{Bcl}-2$ level. In contrast, a study by Liu et al. [102] revealed that NS-398 in the same cell line was able to induce apoptosis but down-regulation of Bcl-2. These results suggest a possible COX-2-independent effect and strongly recommends considering in parallel other experimental strategies to ascertain the effective role of COX2 in human malignancies [33], such as methodologies based on RNA interference or antisense oligonucleotides. Studies have already suggested these alternative methods. It has been shown that the sensitivity of a human gastric cancer cell line MKN45 to cisplatin (alkylating agent) was increased by COX-2 downregulation with siRNA [35].

\section{Conclusion}

A number of studies suggest that COX-2 inhibition may lead to an inhibition of cell proliferation in different cancer types. The fact that COX-2 inhibition may per se trigger apoptosis of tumor cells and/or sensitize them to cytotoxic treatments is an indication that COX-2 may be a good target in cancer therapy, in order to improve the efficiency of tumor cell death and to reduce tumor progression (see Figure 5 for a synthesis). Accordingly, the combination of selective COX-2 inhibitors with radiotherapy or different chemotherapeutics revealed a sensitization to apoptosis. This effect was also observed with several agents inducing apoptosis in a physiological way, thus suggesting that COX-2 inhibitors used in combination with death receptors agonists might be a novel approach to elicit apoptosis of cancer cells. However, the fact that COX-2 inhibitors can mediate their effects by COX-2-independent mechanisms suggests caution in the interpretation of the data.

Nowadays, selective COX-2 inhibitors have been included in several clinical assays. Some of them effectively increase the efficiency of radiotherapy and chemotherapy [172]. For example, celecoxib is in a clinical phase II assay in combination with Paclitaxel, carboplatin, and radiotherapy for patients with inoperable stage IIIA/B nonsmall cell lung cancer [172]. These clinical assays confirm that COX-2 inhibition may be a promising field in cancer treatment. However, the selective COX-2 inhibitors are responsible for side effects, including an increasing risk of cardiovascular complications $[67,68]$. It is hoped that other methods to inhibit COX-2 will be developed. To this purpose, RNA interference using vehicle (i.e., adenovirus) as well as natural compounds were suggested by some studies $[35,76]$, as alternative and promising strategy.

\section{Conflicts of Interest}

The authors have no actual or potential conflict of interest.

\section{Acknowledgments}

C. Sobolewski. and C. Cerella are recipients of doctoral and postdoctoral Télévie gtrants, respectively. Research at the Laboratoire de Biologie Moléculaire et Cellulaire du Cancer (LBMCC) is financially supported by "Recherche Cancer et Sang" foundation, by the "Recherches Scientifiques Luxembourg" association, by "Een Haerz fir kriibskrank Kanner" association, by the Action Lions "Vaincre le Cancer" association and by Télévie Luxembourg. The authors are particularly grateful to Fonds National pour la Recherche (FNR) Luxembourg, for additional financial support provided for this publication.

\section{References}

[1] V. I. Kulinsky, "Biochemical aspects of inflammation," Biochemistry, vol. 72, no. 6, pp. 595-607, 2007.

[2] R. N. DuBois, S. B. Abramson, L. Crofford, et al., "Cyclooxygenase in biology and disease," FASEB Journal, vol. 12, no. 12, pp. 1063-1073, 1998.

[3] F. Balkwill and A. Mantovani, "Inflammation and cancer: back to Virchow?" The Lancet, vol. 357, no. 9255, pp. 539545, 2001.

[4] L. K. Dennis, C. F. Lynch, and J. C. Torner, "Epidemiologic association between prostatitis and prostate cancer," Urology, vol. 60, no. 1, pp. 78-83, 2002.

[5] L. R. Howe, "Inflammation and breast cancer. Cyclooxygenase/prostaglandin signaling and breast cancer," Breast Cancer Research, vol. 9, no. 4, p. 210, 2007. 
[6] L. M. Coussens and Z. Werb, "Inflammation and cancer," Nature, vol. 420, no. 6917, pp. 860-867, 2002.

[7] M. Suganuma, S. Okabe, M. W. Marino, A. Sakai, E. Sueoka, and H. Fujiki, "Essential role of tumor necrosis factor $\alpha$ (TNF- $\alpha$ ) in tumor promotion as revealed by TNF- $\alpha$-deficient mice," Cancer Research, vol. 59, no. 18, pp. 4516-4518, 1999.

[8] M. Yao, E. C. Lam, C. R. Kelly, W. Zhou, and M. M. Wolfe, "Cyclooxygenase-2 selective inhibition with NS-398 suppresses proliferation and invasiveness and delays liver metastasis in colorectal cancer," British Journal of Cancer, vol. 90, no. 3, pp. 712-719, 2004.

[9] R. N. DuBois and W. E. Smalley, "Cyclooxygenase, NSAIDs, and colorectal cancer," Journal of Gastroenterology, vol. 31, no. 6, pp. 898-906, 1996.

[10] A. L. Eisinger, S. M. Prescott, D. A. Jones, and D. M. Stafforini, "The role of cyclooxygenase-2 and prostaglandins in colon cancer," Prostaglandins and Other Lipid Mediators, vol. 82, no. 1-4, pp. 147-154, 2007.

[11] G. Steinbach, P. M. Lynch, R. K. S. Phillips, et al., "The effect of celecoxib, a cyclooxygenase-2 inhibitor, in familial adenomatous polyposis," The New England Journal of Medicine, vol. 342, no. 26, pp. 1946-1952, 2000.

[12] S. P. Hussain and C. C. Harris, "Inflammation and cancer: an ancient link with novel potentials," International Journal of Cancer, vol. 121, no. 11, pp. 2373-2380, 2007.

[13] S. Cristofanon, F. Morceau, A. I. Scovassi, M. Dicato, L. Ghibelli, and M. Diederich, "Oxidative, multistep activation of the noncanonical NF- $\kappa$ B pathway via disulfide Bcl-3/p50 complex," FASEB Journal, vol. 23, pp. 45-57, 2009.

[14] R. Chen, A. B. Alvero, D. A. Silasi, and G. Mor, "Inflammation, cancer and chemoresistance: taking advantage of the toll-like receptor signaling pathway," American Journal of Reproductive Immunology, vol. 57, no. 2, pp. 93-107, 2007.

[15] M. D'Alessio, C. Cerella, C. Amici, et al., "Glutathione depletion up-regulates Bcl-2 in BSO-resistant cells," FASEB Journal, vol. 18, no. 13, pp. 1609-1611, 2004.

[16] W. W. Lin and M. Karin, "A cytokine-mediated link between innate immunity, inflammation, and cancer," Journal of Clinical Investigation, vol. 117, no. 5, pp. 1175-1183, 2007.

[17] E. Pikarsky, R. M. Porat, I. Stein, et al., "NF- $\kappa$ B functions as a tumour promoter in inflammation-associated cancer," Nature, vol. 431, no. 7007, pp. 461-466, 2004.

[18] S. T. Palayoor, M. Y. Youmell, S. K. Calderwood, C. N. Coleman, and B. D. Price, "Constitutive activation of $\mathrm{I} \kappa \mathrm{B}$ kinase $\alpha$ and NF- $\kappa$ B in prostate cancer cells is inhibited by ibuprofen," Oncogene, vol. 18, no. 51, pp. 7389-7394, 1999.

[19] U. Kordes, D. Krappmann, V. Heissmeyer, W. D. Ludwig, and C. Scheidereit, "Transcription factor NF- $\kappa$ B is constitutively activated in acute lymphoblastic leukemia cells," Leukemia, vol. 14, no. 3, pp. 399-402, 2000.

[20] G. Tricot, "New insights into role of microenvironment in multiple myeloma," The Lancet, vol. 355, no. 9200, pp. 248 250, 2000.

[21] N. V. Chandrasekharan and D. L. Simmons, "The cyclooxygenases," Genome Biology, vol. 5, no. 9, article 241, 2004.

[22] S. Narumiya and G. A. FitzGerald, "Genetic and pharmacological analysis of prostanoid receptor function," Journal of Clinical Investigation, vol. 108, no. 1, pp. 25-30, 2001.

[23] R. G. Ramsay, D. Ciznadija, M. Vanevski, and T. Mantamadiotis, "Transcriptional regulation of cyclo-oxygenase expression: three pillars of control," International Journal of Immunopathology and Pharmacology, vol. 16, no. 2, supplement, pp. 59-67, 2003.
[24] B. Hinz and K. Brune, "Cyclooxygenase-2-10 years later," Journal of Pharmacology and Experimental Therapeutics, vol. 300, no. 2, pp. 367-375, 2002.

[25] R. G. Kurumbail, A. M. Stevens, J. K. Gierse, et al., "Structural basis for selective inhibition of cyciooxygenase- 2 by antiinflammatory agents," Nature, vol. 384, no. 6610, pp. 644648, 1996.

[26] F. H. Sarkar, S. Adsule, Y. Li, and S. Padhye, "Back to the future: COX-2 inhibitors for chemoprevention and cancer therapy," Mini-Reviews in Medicinal Chemistry, vol. 7, no. 6, pp. 599-608, 2007.

[27] B. Kis, J. A. Snipes, T. Isse, K. Nagy, and D. W. Busija, "Putative cyclooxygenase-3 expression in rat brain cells," Journal of Cerebral Blood Flow and Metabolism, vol. 23, no. 11, pp. 1287-1292, 2003.

[28] N. V. Chandrasekharan, H. Dai, K. L. T. Roos, et al., "COX3 , a cyclooxygenase-1 variant inhibited by acetaminophen and other analgesic/antipyretic drugs: cloning, structure, and expression," Proceedings of the National Academy of Sciences of the United States of America, vol. 99, no. 21, pp. 13926-13931, 2002.

[29] B. Hinz, O. Cheremina, and K. Brune, "Acetaminophen (paracetamol) is a selective cyclooxygenase-2 inhibitor in man," FASEB Journal, vol. 22, no. 2, pp. 383-390, 2008.

[30] Y. Cao and S. M. Prescott, "Many actions of cyclooxygenase2 in cellular dynamics and in cancer," Journal of Cellular Physiology, vol. 190, no. 3, pp. 279-286, 2002.

[31] A. Ristimaki, A. Sivula, J. Lundin, et al., "Prognostic significance of elevated cyclooxygenase- 2 expression in breast cancer," Cancer Research, vol. 62, no. 3, pp. 632-635, 2002.

[32] P. Secchiero, E. Barbarotto, A. Gonelli, et al., "Potential pathogenetic implications of cyclooxygenase-2 overexpression in B chronic lymphoid leukemia cells," American Journal of Pathology, vol. 167, no. 6, pp. 1599-1607, 2005.

[33] Y. Nakanishi, R. Kamijo, K. Takizawa, M. Hatori, and M. Nagumo, "Inhibitors of cyclooxygenase-2 (COX-2) suppressed the proliferation and differentiation of human leukaemia cell lines," European Journal of Cancer, vol. 37, no. 12, pp. 1570-1578, 2001.

[34] T. Wun, H. McKnight, and J. M. Tuscano, "Increased cyclooxygenase-2 (COX-2): a potential role in the pathogenesis of lymphoma," Leukemia Research, vol. 28, no. 2, pp. 179190, 2004.

[35] M. W. Chan, C. Y. Wong, A. S. Cheng, et al., "Targeted inhibition of COX-2 expression by RNA interference suppresses tumor growth and potentiates chemosensitivity to cisplatin in human gastric cancer cells," Oncology Reports, vol. 18, no. 6, pp. 1557-1562, 2007.

[36] G. E. Johnson, V. N. Ivanov, and T. K. Hei, "Radiosensitization of melanoma cells through combined inhibition of protein regulators of cell survival," Apoptosis, vol. 13, no. 6, pp. 790-802, 2008.

[37] S. T. Palayoor, M. J. Arayankalayil, A. Shoaibi, and C. N. Coleman, "Radiation sensitivity of human carcinoma cells transfected with small interfering RNA targeted against cyclooxygenase-2," Clinical Cancer Research, vol. 11, no. 19, pp. 6980-6986, 2005.

[38] M. Philip, D. A. Rowley, and H. Schreiber, "Inflammation as a tumor promoter in cancer induction," Seminars in Cancer Biology, vol. 14, no. 6, pp. 433-439, 2004.

[39] A. Zrieki, R. Farinotti, and M. Buyse, "Cyclooxygenase inhibitors down regulate P-glycoprotein in human colorectal caco-2 cell line," Pharmaceutical Research, vol. 25, no. 9, pp. 1991-2001, 2008. 
[40] E. M. Choi, S. J. Kwak, Y. M. Kim, et al., "COX-2 inhibits anoikis by activation of the PI-3K/Akt pathway in human bladder cancer cells," Experimental and Molecular Medicine, vol. 37, no. 3, pp. 199-203, 2005.

[41] R. M. Breyer, C. K. Bagdassarian, S. A. Myers, and M. D. Breyer, "Prostanoid receptors: subtypes and signaling," Annual Review of Pharmacology and Toxicology, vol. 41, pp. 661-690, 2001.

[42] J. Grossmann, "Molecular mechanisms of "detachmentinduced apoptosis-anoikis"', Apoptosis, vol. 7, no. 3, pp. 247-260, 2002.

[43] J. R. Woodgett, "Regulation and functions of the glycogen synthase kinase-3 subfamily," Seminars in Cancer Biology, vol. 5, no. 4, pp. 269-275, 1994.

[44] N. K. Boughton Smith, C. J. Hawkey, and B. J. R. Whittle, "Biosynthesis of lipoxygenase and cyclo-oxygenase products from [14C]-arachidonic acid by human colonic mucosa," Gut, vol. 24, no. 12, pp. 1176-1182, 1983.

[45] V. W. Yang, J. M. Shields, S. R. Hamilton, et al., "Sizedependent increase in prostanoid levels in adenomas of patients with familial adenomatous polyposis," Cancer Research, vol. 58, no. 8, pp. 1750-1753, 1998.

[46] H. Sheng, J. Shao, J. D. Morrow, R. D. Beauchamp, and R. N. DuBois, "Modulation of apoptosis and Bcl-2 expression by prostaglandin $\mathrm{E}_{2}$ in human colon cancer cells," Cancer Research, vol. 58, no. 2, pp. 362-366, 1998.

[47] G. A. Doherty, S. M. Byrne, E. S. Molloy, et al., "Proneoplastic effects of $\mathrm{PGE}_{2}$ mediated by $\mathrm{EP} 4$ receptor in colorectal cancer," BMC Cancer, vol. 9, article 207, 2009.

[48] L. Damstrup, S. K. Kuwada, P. J. Dempsey, et al., "Amphiregulin acts as an autocrine growth factor in two human polarizing colon cancer lines that exhibit domain selective EGF receptor mitogenesis," British Journal of Cancer, vol. 80, no. 7, pp. 1012-1019, 1999.

[49] Q. B. She, D. B. Solit, Q. Ye, K. E. O’Reilly, J. Lobo, and $\mathrm{N}$. Rosen, "The BAD protein integrates survival signaling by EGFR/MAPK and PI3K/Akt kinase pathways in PTENdeficient tumor cells," Cancer Cell, vol. 8, no. 4, pp. 287-297, 2005.

[50] T. G. Tessner, F. Muhale, T. E. Riehl, S. Anant, and W. F. Stenson, "Prostaglandin $\mathrm{E}_{2}$ reduces radiation-induced epithelial apoptosis through a mechanism involving AKT activation and Bax translocation," Journal of Clinical Investigation, vol. 114, no. 11, pp. 1676-1685, 2004.

[51] A. Burlacu, "Regulation of apoptosis by Bcl-2 family proteins," Journal of Cellular and Molecular Medicine, vol. 7, no. 3, pp. 249-257, 2003.

[52] T. Yamaki, K. Endoh, M. Miyahara, et al., "Prostaglandin $\mathrm{E}_{2}$ activates Src signaling in lung adenocarcinoma cell via $\mathrm{EP}_{3}$," Cancer Letters, vol. 214, no. 1, pp. 115-120, 2004.

[53] L. P. Billen, C. L. Kokoski, J. F. Lovell, B. Leber, and D. W. Andrews, "Bcl-XL inhibits membrane permeabilization by competing with Bax," PLoS Biology, vol. 6, no. 6, article e147, 2008.

[54] Z. A. Stewart, M. D. Westfall, and J. A. Pietenpol, "Cell-cycle dysregulation and anticancer therapy," Trends in Pharmacological Sciences, vol. 24, no. 3, pp. 139-145, 2003.

[55] M. D. Larrea, J. Liang, T. Da Silva, et al., "Phosphorylation of p $27^{\text {Kip1 }}$ regulates assembly and activation of cyclin D1-Cdk4," Molecular and Cellular Biology, vol. 28, no. 20, pp. 6462-6472, 2008.

[56] M. Pagano, S. W. Tam, A. M. Theodoras, et al., "Role of the ubiquitin-proteasome pathway in regulating abundance of the cyclin-dependent kinase inhibitor p27," Science, vol. 269, no. 5224, pp. 682-685, 1995.

[57] J. L. Bos, "ras Oncogenes in human cancer: a review," Cancer Research, vol. 49, no. 17, pp. 4682-4689, 1989.

[58] C. Tsatsanis, A. Androulidaki, M. Venihaki, and A. N. Margioris, "Signalling networks regulating cyclooxygenase2," International Journal of Biochemistry and Cell Biology, vol. 38, no. 10, pp. 1654-1661, 2006.

[59] T. Yano, G. Zissel, J. Muller-Qernheim, S. Jae Shin, H. Satoh, and T. Ichikawa, "Prostaglandin $\mathrm{E}_{2}$ reinforces the activation of Ras signal pathway in lung adenocarcinoma cells via $\mathrm{EP}_{3}$," FEBS Letters, vol. 518, no. 1-3, pp. 154-158, 2002.

[60] M. R. Junttila and J. Westermarck, "Mechanisms of MYC stabilization in human malignancies," Cell Cycle, vol. 7, no. 5, pp. 592-596, 2008.

[61] X. Ma, N. Kundu, S. Rifat, T. Walser, and A. M. Fulton, "Prostaglandin E receptor $\mathrm{EP}_{4}$ antagonism inhibits breast cancer metastasis," Cancer Research, vol. 66, no. 6, pp. 29232927, 2006.

[62] M. Majima, I. Hayashi, M. Muramatsu, J. Katada, S. Yamashina, and M. Katori, "Cyclo-oxygenase-2 enhances basic fibroblast growth factor-induced angiogenesis through induction of vascular endothelial growth factor in rat sponge implants," British Journal of Pharmacology, vol. 130, no. 3, pp. 641-649, 2000.

[63] J. Folkman, "Tumor angiogenesis: therapeutic implications," The New England Journal of Medicine, vol. 285, no. 21, pp. 1182-1186, 1971.

[64] G. A. Green, "Understanding NSAIDs: from aspirin to COX2," Clinical Cornerstone, vol. 3, no. 5, pp. 50-59, 2001.

[65] S. H. Ferreira, S. Moncada, and J. R. Vane, "Indomethacin and aspirin abolish prostaglandin release from the spleen," Nature, vol. 231, no. 25, pp. 237-239, 1971.

[66] S. Pasa, K. Bayan, M. Kucukoner, et al., "The effects of nonsteroidal anti-inflammatory drugs on platelet function and severity of upper gastrointestinal haemorrhage," Journal of Thrombosis and Thrombolysis, vol. 28, no. 1, pp. 83-89, 2009.

[67] M. Hudson, E. Rahme, H. Richard, and L. Pilote, "Risk of congestive heart failure with nonsteroidal antiinflammatory drugs and selective cyclooxygenase 2 inhibitors: a class effect?" Arthritis Care and Research, vol. 57, no. 3, pp. 516523, 2007.

[68] S. Grosch, T. J. Maier, S. Schiffmann, and G. Geisslinger, "Cyclooxygenase-2 (COX-2)-independent anticarcinogenic effects of selective COX-2 inhibitors," Journal of the National Cancer Institute, vol. 98, no. 11, pp. 736-747, 2006.

[69] W. B. White, G. Faich, A. Whelton, et al., "Comparison of thromboembolic events in patients treated with celecoxib, a cyclooxygenase-2 specific inhibitor, versus ibuprofen or diclofenac," American Journal of Cardiology, vol. 89, no. 4, pp. 425-430, 2002.

[70] M. E. Farkouh, F. W. A. Verheugt, S. Ruland, et al., "A comparison of the blood pressure changes of lumiracoxib with those of ibuprofen and naproxen," Journal of Clinical Hypertension, vol. 10, no. 8, pp. 592-602, 2008.

[71] A. Whelton, J. G. Fort, J. A. Puma, D. Normandin, A. E. Bello, and K. M. Verburg, "Cyclooxygenase-2-specific inhibitors and cardiorenal function: a randomized, controlled trial of celecoxib and rofecoxib in older hypertensive osteoarthritis patients," American Journal of Therapeutics, vol. 8, no. 2, pp. 85-95, 2001.

[72] T. Juhlin, S. Björkman, and P. Höglund, "Cyclooxygenase inhibition causes marked impairment of renal function in 
elderly subjects treated with diuretics and ACE-inhibitors," European Journal of Heart Failure, vol. 7, no. 6, pp. 10491056, 2005.

[73] S. Z. Zhao, M. W. Reynolds, J. Lefkowith, A. Whelton, and F. M. Arellano, "A comparison of renal-related adverse drug reactions between rofecoxib and celecoxib, based on the World Health Organization/Uppsala Monitoring Centre safety database," Clinical Therapeutics, vol. 23, no. 9, pp. 1478-1491, 2001.

[74] T. P. van Staa, L. Smeeth, I. Persson, J. Parkinson, and H. G. M. Leufkens, "What is the harm-benefit ratio of Cox2 inhibitors?" International Journal of Epidemiology, vol. 37, no. 2, pp. 405-413, 2008.

[75] B. D. De Smet, A. M. Fendrick, J. G. Stevenson, and S. J. Bernstein, "Over and under-utilization of cyclooxygenase-2 selective inhibitors by primary care physicians and specialists: the tortoise and the hare revisited," Journal of General Internal Medicine, vol. 21, no. 7, pp. 694-697, 2006.

[76] A. Strillacci, C. Griffoni, E. Spisni, M. C. Manara, and V. Tomasi, "RNA interference as a key to knockdown overexpressed cyclooxygenase-2 gene in tumour cells," British Journal of Cancer, vol. 94, no. 9, pp. 1300-1310, 2006.

[77] H. L. Peng, G. S. Zhang, J. H. Liu, F. J. Gong, and R. J. Li, "Dup-697, a specific COX-2 inhibitor, suppresses growth and induces apoptosis on K562 leukemia cells by cell-cycle arrest and caspase-8 activation," Annals of Hematology, vol. 87, no. 2, pp. 121-129, 2008.

[78] H. Sheng, J. Shao, S. C. Kirkland, et al., "Inhibition of human colon cancer cell growth by selective inhibition of cyclooxygenase-2," Journal of Clinical Investigation, vol. 99, no. 9, pp. 2254-2259, 1997.

[79] H. Amano, I. Hayashi, H. Endo, et al., "Host prostaglandin $\mathrm{E}_{2}$-EP3 signaling regulates tumor-associated angiogenesis and tumor growth," Journal of Experimental Medicine, vol. 197, no. 2, pp. 221-232, 2003.

[80] H. Hochegger, S. Takeda, and T. Hunt, "Cyclin-dependent kinases and cell-cycle transitions: does one fit all?" Nature Reviews Molecular Cell Biology, vol. 9, no. 11, pp. 910-916, 2008.

[81] D. Cobrinik, "Pocket proteins and cell cycle control," Oncogene, vol. 24, no. 17, pp. 2796-2809, 2005.

[82] Z. Kelman, "PCNA: structure, functions and interactions," Oncogene, vol. 14, no. 6, pp. 629-640, 1997.

[83] W. R. Taylor and G. R. Stark, "Regulation of the G2/M transition by p53," Oncogene, vol. 20, no. 15, pp. 1803-1815, 2001.

[84] J. Li, X. Chen, X. Dong, Z. Xu, H. Jiang, and X. Sun, “Specific COX-2 inhibitor, meloxicam, suppresses proliferation and induces apoptosis in human HepG2 hepatocellular carcinoma cells," Journal of Gastroenterology and Hepatology, vol. 21, no. 12, pp. 1814-1820, 2006.

[85] M. D. Castellone, H. Teramoto, B. O. Williams, K. M. Druey, and J. S. Gutkind, "Prostaglandin $\mathrm{E}_{2}$ promotes colon cancer cell growth through a $\mathrm{G}_{\mathrm{s}}$-axin- $\beta$-catenin signaling axis," Science, vol. 310, no. 5753, pp. 1504-1510, 2005.

[86] B. Xin, Y. Yokoyama, T. Shigeto, and H. Mizunuma, "Antitumor effect of non-steroidal anti-inflammatory drugs on human ovarian cancers," Pathology and Oncology Research, vol. 13, no. 4, pp. 365-369, 2007.

[87] C. Falandry, P. A. Canney, G. Freyer, and L. Y. Dirix, "Role of combination therapy with aromatase and cyclooxygenase-2 inhibitors in patients with metastatic breast cancer," Annals of Oncology, vol. 20, no. 4, pp. 615-620, 2009.
[88] X. F. Xu, C. G. Xie, X. P. Wang, et al., "Selective inhibition of cyclooxygenase-2 suppresses the growth of pancreatic cancer cells in vitro and in vivo," Tohoku Journal of Experimental Medicine, vol. 215, no. 2, pp. 149-157, 2008.

[89] G. S. Zhang, D. S. Liu, C. W. Dai, and R. J. Li, "Antitumor effects of celecoxib on K562 leukemia cells are mediated by cell-cycle arrest, caspase-3 activation, and downregulation of Cox-2 expression and are synergistic with hydroxyurea or imatinib," American Journal of Hematology, vol. 81, no. 4, pp. 242-255, 2006.

[90] S. Dimmeler, K. Breitschopf, J. Haendeler, and A. M. Zeiher, "Dephosphorylation targets $\mathrm{Bcl}-2$ for ubiquitin-dependent degradation: a link between the apoptosome and the proteasome pathway," Journal of Experimental Medicine, vol. 189, no. 11, pp. 1815-1822, 1999.

[91] G. Majno and I. Joris, "Apoptosis, oncosis, and necrosis: an overview of cell death," American Journal of Pathology, vol. 146, no. 1, pp. 3-15, 1995.

[92] J. F. Fullard, A. Kale, and N. E. Baker, "Clearance of apoptotic corpses," Apoptosis, vol. 14, no. 8, pp. 1029-1037, 2009.

[93] S. Shimohama, "Apoptosis in Alzheimer's disease-an update," Apoptosis, vol. 5, no. 1, pp. 9-16, 2000.

[94] S. Coppola and L. Ghibelli, "GSH extrusion and the mitochondrial pathway of apoptotic signalling," Biochemical Society Transactions, vol. 28, no. 2, pp. 56-61, 2000.

[95] D. C. Henshall, D. P. Bonislawski, S. L. Skradski, J. Q. Lan, R. Meller, and R. P. Simon, "Cleavage of bid may amplify caspase-8-induced neuronal death following focally evoked limbic seizures," Neurobiology of Disease, vol. 8, no. 4, pp. 568-580, 2001.

[96] Y. J. Cha, H. S. Kim, H. Rhim, B. E. Kim, S. W. Jeong, and I. K. Kim, "Activation of caspase-8 in 3-deazaadenosine-induced apoptosis of U-937 cells occurs downstream of caspase3 and caspase-9 without Fas receptor-ligand interaction," Experimental and Molecular Medicine, vol. 33, no. 4, pp. 284292, 2001.

[97] L. Ghibelli, C. Fanelli, G. Rotilio, et al., "Rescue of cells from apoptosis by inhibition of active GSH extrusion," FASEB Journal, vol. 12, no. 6, pp. 479-486, 1998.

[98] M. D’Alessio, M. De Nicola, S. Coppola, et al., "Oxidative Bax dimerization promotes its translocation to mitochondria independently of apoptosis," FASEB Journal, vol. 19, no. 11, pp. 1504-1506, 2005.

[99] L. Zhou and D. C. Chang, "Dynamics and structure of the Bax-Bak complex responsible for releasing mitochondrial proteins during apoptosis," Journal of Cell Science, vol. 121, no. 13, pp. 2186-2196, 2008.

[100] I. Tamm, Y. Wang, E. Sausville, et al., "IAP-family protein survivin inhibits caspase activity and apoptosis induced by Fas (CD95), Bax, caspases, and anticancer drugs," Cancer Research, vol. 58, no. 23, pp. 5315-5320, 1998.

[101] J. Chai, C. Du, J. W. Wu, S. Kyin, X. Wang, and Y. Shi, "Structural and biochemical basis of apoptotic activation by Smac/DIABLO,” Nature, vol. 406, no. 6798, pp. 855-862, 2000.

[102] X. H. Liu, S. Yao, A. Kirschenbaum, and A. C. Levine, "NS398, a selective cyclooxygenase-2 inhibitor, induces apoptosis and down-regulates Bcl-2 expression in LNCaP cells," Cancer Research, vol. 58, no. 19, pp. 4245-4249, 1998.

[103] Y. Cao, A. T. Pearman, G. A. Zimmerman, T. M. McIntyre, and S. M. Prescott, "Intracellular unesterified arachidonic acid signals apoptosis," Proceedings of the National Academy of Sciences of the United States of America, vol. 97, no. 21, pp. $11280-11285,2000$. 
[104] S. Jayadev, C. M. Linardic, and Y. A. Hannun, "Identification of arachidonic acid as a mediator of sphingomyelin hydrolysis in response to tumor necrosis factor $\alpha$, The Journal of Biological Chemistry, vol. 269, no. 8, pp. 5757-5763, 1994.

[105] B. J. Pettus, C. E. Chalfant, and Y. A. Hannun, "Ceramide in apoptosis: an overview and current perspectives," Biochimica et Biophysica Acta, vol. 1585, no. 2-3, pp. 114-125, 2002.

[106] T. A. Chan, P. J. Morin, B. Vogelstein, and K. W. Kinzler, "Mechanisms underlying nonsteroidal antiinflammatory drug-mediated apoptosis," Proceedings of the National Academy of Sciences of the United States of America, vol. 95, no. 2, pp. 681-686, 1998.

[107] B. Brüne, A. von Knethen, and K. B. Sandau, "Nitric oxide (NO): an effector of apoptosis," Cell Death and Differentiation, vol. 6, no. 10, pp. 969-975, 1999.

[108] Y. W. E. Chang, R. Jakobi, A. McGinty, M. Foschi, M. J. Dunn, and A. Sorokin, "Cyclooxygenase 2 promotes cell survival by stimulation of dynein light chain expression and inhibition of neuronal nitric oxide synthase activity," Molecular and Cellular Biology, vol. 20, no. 22, pp. 8571-8579, 2000.

[109] L. M. S. Lau, J. K. Wolter, J. T. M. L. Lau, et al., "Cyclooxygenase inhibitors differentially modulate p73 isoforms in neuroblastoma," Oncogene, vol. 28, no. 19, pp. 2024-2033, 2009.

[110] M. S. Irwin and F. D. Miller, "p73: regulator in cancer and neural development," Cell Death and Differentiation, vol. 11, supplement 1, pp. S17-S22, 2004.

[111] N. Kim, C. H. Kim, D. W. Ahn, et al., "Anti-gastric cancer effects of celecoxib, a selective COX-2 inhibitor, through inhibition of Akt signaling," Journal of Gastroenterology and Hepatology, vol. 24, no. 3, pp. 480-487, 2009.

[112] B. Liu, Z. 1. Shi, J. Feng, and H. M. Tao, "Celecoxib, a cyclooxygenase-2 inhibitor, induces apoptosis in human osteosarcoma cell line MG-63 via down-regulation of PI3K/Akt," Cell Biology International, vol. 32, no. 5, pp. 494501, 2008.

[113] A. L. Hsu, T. T. Ching, D. S. Wang, X. Song, V. M. Rangnekar, and C. S. Chen, "The cyclooxygenase-2 inhibitor celecoxib induces apoptosis by blocking Akt activation in human prostate cancer cells independently of Bcl-2," The Journal of Biological Chemistry, vol. 275, no. 15, pp. 11397-11403, 2000.

[114] S. Honjo, M. Osaki, T. D. Ardyanto, T. Hiramatsu, N. Maeta, and H. Ito, "COX-2 inhibitor, NS398, enhances fas-mediated apoptosis via modulation of the PTEN-Akt pathway in human gastric carcinoma cell lines," DNA and Cell Biology, vol. 24, no. 3, pp. 141-147, 2005.

[115] J. Y. Liou, D. Ghelani, S. Yeh, and K. K. Wu, "Nonsteroidal anti-inflammatory drugs induce colorectal cancer cell apoptosis by suppressing 14-3-3e," Cancer Research, vol. 67, no. 7, pp. 3185-3191, 2007.

[116] Y. Yamamoto, M. J. Yin, K. M. Lin, and R. B. Gaynor, "Sulindac inhibits activation of the NF- $\kappa \mathrm{B}$ pathway," The Journal of Biological Chemistry, vol. 274, no. 38, pp. 2730727314, 1999.

[117] B. Poligone and A. S. Baldwin, "Positive and negative regulation of NF- $\kappa$ B by COX-2: roles of different prostaglandins," The Journal of Biological Chemistry, vol. 276, no. 42, pp. 38658-38664, 2001.

[118] M. K. Park, Y. J. Kang, Y. M. Ha, et al., "EP 2 receptor activation by prostaglandin $\mathrm{E}_{2}$ leads to induction of $\mathrm{HO}-1$ via PKA and PI3K pathways in C6 cells," Biochemical and Biophysical Research Communications, vol. 379, no. 4, pp. 1043-1047, 2009.
[119] S. Martin, D. C. Phillips, K. Szekely-Szucs, L. Elghazi, F. Desmots, and J. A. Houghton, "Cyclooxygenase-2 inhibition sensitizes human colon carcinoma cells to TRAILinduced apoptosis through clustering of DR5 and concentrating death-inducing signaling complex components into ceramide-enriched caveolae," Cancer Research, vol. 65, no. 24, pp. 11447-11458, 2005.

[120] R. Tang, A.-M. Faussat, J.-Y. Perrot, et al., "Zosuquidar restores drug sensitivity in P-glycoprotein expressing acute myeloid leukemia (AML)," BMC Cancer, vol. 8, article 51, 2008.

[121] Y. Yamanaka, K. Shiraki, T. Inoue, et al., "COX-2 inhibitors sensitize human hepatocellular carcinoma cells to TRAILinduced apoptosis," International Journal of Molecular Medicine, vol. 18, no. 1, pp. 41-47, 2006.

[122] M. Casado, B. Molla, R. Roy, et al., "Protection against Fas-induced liver apoptosis in transgenic mice expressing cyclooxygenase 2 in hepatocytes," Hepatology, vol. 45, no. 3, pp. 631-638, 2007.

[123] U. C. Nzeako, M. E. Guicciardi, J. H. Yoon, S. F. Bronk, and G. J. Gores, "COX-2 inhibits Fas-mediated apoptosis in cholangiocarcinoma cells," Hepatology, vol. 35, no. 3, pp. 552-559, 2002.

[124] S. M. Frisch and E. Ruoslahti, "Integrins and anoikis," Current Opinion in Cell Biology, vol. 9, no. 5, pp. 701-706, 1997.

[125] F. G. Giancotti and E. Ruoslahti, "Integrin signaling," Science, vol. 285, no. 5430, pp. 1028-1032, 1999.

[126] R. R. Joseph, E. Yazer, Y. Hanakawa, and A. W. Stadnyk, "Prostaglandins and activation of AC/cAMP prevents anoikis in IEC-18," Apoptosis, vol. 10, no. 6, pp. 1221-1233, 2005.

[127] S. Kanayama, Y. Yamada, R. Kawaguchi, Y. Tsuji, S. Haruta, and H. Kobayashi, "Hepatocyte growth factor induces anoikis resistance by up-regulation of cyclooxygenase-2 expression in uterine endometrial cancer cells," Oncology Reports, vol. 19, no. 1, pp. 117-122, 2008.

[128] L. Beviglia, K. Matsumoto, C. S. Lin, B. L. Ziober, and R. H. Kramer, "Expression of the c-Met/HGF receptor in human breast carcinoma: correlation with tumor progression," International Journal of Cancer, vol. 74, no. 3, pp. 301-309, 1997.

[129] G. Dong, Z. Chen, Z. Y. Li, N. T. Yeh, C. C. Bancroft, and C. Van Waes, "Hepatocyte growth factor/scatter factor-induced activation of MEK and PI3K signal pathways contributes to expression of proangiogenic cytokines interleukin- 8 and vascular endothelial growth factor in head and neck squamous cell carcinoma," Cancer Research, vol. 61, no. 15, pp. 59115918, 2001.

[130] S. Wagatsuma, R. Konno, S. Sato, and A. Yajima, "Tumor angiogenesis, hepatocyte growth factor, and c-Met expression in endometrial carcinoma," Cancer, vol. 82, no. 3, pp. 520530, 1998.

[131] Q. Zeng, L. K. McCauley, and C. Y. Wang, "Hepatocyte growth factor inhibits anoikis by induction of activator protein 1-dependent cyclooxygenase-2: implication in head and neck squamous cell carcinoma progression," The Journal of Biological Chemistry, vol. 277, no. 51, pp. 50137-50142, 2002.

[132] M. C. Maiuri, E. Zalckvar, A. Kimchi, and G. Kroemer, "Self-eating and self-killing: crosstalk between autophagy and apoptosis," Nature Reviews Molecular Cell Biology, vol. 8, no. 9, pp. 741-752, 2007.

[133] C. Bauvy, P. Gane, S. Arico, P. Codogno, and E. Ogier-Denis, "Autophagy delays sulindac sulfide-induced apoptosis in the 
human intestinal colon cancer cell line HT-29," Experimental Cell Research, vol. 268, no. 2, pp. 139-149, 2001.

[134] P. M. Lynch, "COX-2 inhibition in clinical cancer prevention,” Oncology, vol. 15, no. 3, supplement 5, pp. 21-26, 2001.

[135] N. Arber, "Cyclooxygenase-2 inhibitors in colorectal cancer prevention: point," Cancer Epidemiology Biomarkers and Prevention, vol. 17, no. 8, pp. 1852-1857, 2008.

[136] B. Arun and P. Goss, "The role of COX-2 inhibition in breast cancer treatment and prevention," Seminars in Oncology, vol. 31, supplement 7, pp. 22-29, 2004.

[137] D. W. Bell, J. M. Varley, T. E. Szydlo, et al., "Heterozygous germ line hCHK2 mutations in Li-Fraumeni syndrome," Science, vol. 286, no. 5449, pp. 2528-2531, 1999.

[138] K. R. Grimes, G. W. Warren, F. Fang, Y. Xu, and W. H. St Clair, "Cyclooxygenase-2 inhibitor, nimesulide, improves radiation treatment against non-small cell lung cancer both in vitro and in vivo," Oncology Reports, vol. 16, no. 4, pp. 771-776, 2006.

[139] C. Czembirek, C. Eder-Czembirek, B. M. Erovic, et al., "The cyclooxygenase-2 inhibitor nimesulide, a nonsteroidal analgesic, decreases the effect of radiation therapy in headand-neck cancer cells," Strahlentherapie und Onkologie, vol. 185, no. 5, pp. 310-317, 2009.

[140] B. A. Chabner and T. G. Roberts Jr., "Chemotherapy and the war on cancer," Nature Reviews Cancer, vol. 5, no. 1, pp. 6572, 2005.

[141] Y. A. Luqmani, "Mechanisms of drug resistance in cancer chemotherapy," Medical Principles and Practice, vol. 14, supplement 1, pp. 35-48, 2005.

[142] U. Puhlmann, C. Ziemann, G. Ruedell, et al., "Impact of the cyclooxygenase system on doxorubicin-induced functional multidrug resistance 1 overexpression and doxorubicin sensitivity in acute myeloid leukemic HL-60 cells," Journal of Pharmacology and Experimental Therapeutics, vol. 312, no. 1, pp. 346-354, 2005.

[143] V. A. Patel, M. J. Dunn, and A. Sorokin, "Regulation of MDR-1 (P-glycoprotein) by cyclooxygenase-2," The Journal of Biological Chemistry, vol. 277, no. 41, pp. 38915-38920, 2002.

[144] X. J. Chen, W. Xiao, X. Qu, and S. Y. Zhou, "NS-398 enhances the efficacy of gemcitabine against lung adenocarcinoma through up-regulation of $\mathrm{p} 21^{\mathrm{WAF} 1}$ and $\mathrm{p} 27^{\mathrm{KIP1}}$ protein," Neoplasma, vol. 55, no. 3, pp. 200-204, 2008.

[145] T. J. Dougherty, "An update on photodynamic therapy applications," Journal of Clinical Laser Medicine and Surgery, vol. 20, no. 1, pp. 3-7, 2002.

[146] D. E. Dolmans, D. Fukumura, and R. K. Jain, "Photodynamic therapy for cancer," Nature Reviews Cancer, vol. 3, no. 5, pp. 380-387, 2003.

[147] T. J. Dougherty, C. J. Gomer, B. W. Henderson, et al., "Photodynamic therapy," Journal of the National Cancer Institute, vol. 90, pp. 889-905, 1998.

[148] A. Ferrario, A. M. Fisher, N. Rucker, and C. J. Gomer, "Celecoxib and NS-398 enhance photodynamic therapy by increasing in vitro apoptosis and decreasing in vivo inflammatory and angiogenic factors," Cancer Research, vol. 65, no. 20, pp. 9473-9478, 2005.

[149] A. Ferrario, K. Von Tiehl, S. Wong, M. Luna, and C. J. Gomer, "Cyclooxygenase-2 inhibitor treatment enhances photodynamic therapy-mediated tumor response," Cancer Research, vol. 62, no. 14, pp. 3956-3961, 2002.

[150] N. Hendrickx, C. Volanti, U. Moens, et al., "Up-regulation of cyclooxygenase- 2 and apoptosis resistance by p38 MAPK in hypericin-mediated photodynamic therapy of human cancer cells," The Journal of Biological Chemistry, vol. 278, no. 52, pp. 52231-52239, 2003.

[151] M. Lasa, K. R. Mahtani, A. Finch, G. Brewer, J. Saklatvala, and A. R. Clark, "Regulation of cyclooxygenase 2 mRNA stability by the mitogen-activated protein kinase p38 signaling cascade," Molecular and Cellular Biology, vol. 20, no. 12, pp. 4265-4274, 2000.

[152] M. Makowski, T. Grzela, J. Niderla, et al., "Inhibition of cyclooxygenase-2 indirectly potentiates antitumor effects of photodynamic therapy in mice," Clinical Cancer Research, vol. 9, no. 14, pp. 5417-5422, 2003.

[153] M. Tsujii, S. Kawano, S. Tsuji, H. Sawaoka, M. Hori, and R. N. DuBois, "Cyclooxygenase regulates angiogenesis induced by colon cancer cells," Cell, vol. 93, no. 5, pp. 705-716, 1998.

[154] K. Bhui, S. Prasad, J. George, and Y. Shukla, "Bromelain inhibits COX-2 expression by blocking the activation of MAPK regulated NF-kappa B against skin tumor-initiation triggering mitochondrial death pathway," Cancer Letters, vol. 282, no. 2, pp. 167-176, 2009.

[155] N. Kalra, K. Bhui, P. Roy, et al., "Regulation of p53, nuclear factor $\kappa \mathrm{B}$ and cyclooxygenase-2 expression by bromelain through targeting mitogen-activated protein kinase pathway in mouse skin," Toxicology and Applied Pharmacology, vol. 226, no. 1, pp. 30-37, 2008.

[156] M. Singh and N. Singh, "Molecular mechanism of curcumin induced cytotoxicity in human cervical carcinoma cells," Molecular and Cellular Biochemistry, vol. 325, no. 1-2, pp. 107-119, 2009.

[157] Y. E. Marín, B. A. Wall, S. Wang, et al., "Curcumin downregulates the constitutive activity of NF- $\kappa \mathrm{B}$ and induces apoptosis in novel mouse melanoma cells," Melanoma Research, vol. 17, no. 5, pp. 274-283, 2007.

[158] C. Park, D. O. Moon, I. W. Choi, et al., "Curcumin induces apoptosis and inhibits prostaglandin $\mathrm{E}_{2}$ production in synovial fibroblasts of patients with rheumatoid arthritis," International Journal of Molecular Medicine, vol. 20, no. 3, pp. 365-372, 2007.

[159] W. M. Weber, L. A. Hunsaker, A. M. Gonzales, et al., "TPAinduced up-regulation of activator protein-1 can be inhibited or enhanced by analogs of the natural product curcumin," Biochemical Pharmacology, vol. 72, no. 8, pp. 928-940, 2006.

[160] A. Goel, A. K. Prasad, V. S. Parmar, B. Ghosh, and N. Saini, "Apoptogenic effect of 7,8-diacetoxy-4-methylcoumarin and 7,8-diacetoxy-4-methylthiocoumarin in human lung adenocarcinoma cell line: role of NF- $\kappa \mathrm{B}, \mathrm{Akt}$, ROS and MAP kinase pathway," Chemico-Biological Interactions, vol. 179, no. 2-3, pp. 363-374, 2009.

[161] Y. Suh, F. Afaq, J. J. Johnson, and H. Mukhtar, "A plant flavonoid fisetin induces apoptosis in colon cancer cells by inhibition of COX2 and Wnt/EGFR/NF- $\kappa$ B-signaling pathways," Carcinogenesis, vol. 30, no. 2, pp. 300-307, 2009.

[162] D. O. Moon, M. O. Kim, S. H. Kang, Y. H. Choi, and G. Y. Kim, "Sulforaphane suppresses TNF- $\alpha$-mediated activation of NF- $\kappa \mathrm{B}$ and induces apoptosis through activation of reactive oxygen species-dependent caspase-3," Cancer Letters, vol. 274, no. 1, pp. 132-142, 2009.

[163] S. Y. Nam, J. S. Kim, J. M. Kim, et al., "DA-6034, a derivative of flavonoid, prevents and ameliorates dextran sulfate sodium-induced colitis and inhibits colon carcinogenesis," Experimental Biology and Medicine, vol. 233, no. 2, pp. 180191, 2008.

[164] C. E. Harper, B. B. Patel, J. Wang, I. A. Eltoum, and C. A. Lamartiniere, "Epigallocatechin-3-gallate suppresses early stage, but not late stage prostate cancer in TRAMP mice: 
mechanisms of action," Prostate, vol. 67, no. 14, pp. 15761589, 2007.

[165] V. M. Adhami, A. Malik, N. Zaman, et al., "Combined inhibitory effects of green tea polyphenols and selective cyclooxygenase- 2 inhibitors on the growth of human prostate cancer cells both in vitro and in vivo," Clinical Cancer Research, vol. 13, no. 5, pp. 1611-1619, 2007.

[166] M. K. Pandey, S. K. Sandur, B. Sung, G. Sethi, A. B. Kunnumakkara, and B. B. Aggarwal, "Butein, a tetrahydroxychalcone, inhibits nuclear factor (NF) $\kappa \mathrm{B}$ and NF- $\kappa \mathrm{B}-$ regulated gene expression through direct inhibition of $\mathrm{I} \kappa \mathrm{B} \alpha$ kinase $\beta$ on cysteine 179 residue," The Journal of Biological Chemistry, vol. 282, no. 24, pp. 17340-17350, 2007.

[167] K. Hostanska, G. Jurgenliemk, G. Abel, A. Nahrstedt, and R. Saller, "Willow bark extract (BNO1455) and its fractions suppress growth and induce apoptosis in human colon and lung cancer cells," Cancer Detection and Prevention, vol. 31, no. 2, pp. 129-139, 2007.

[168] J. Liang and J. M. Slingerland, "Multiple roles of the $\mathrm{PI} 3 \mathrm{~K} / \mathrm{PKB}$ (Akt) pathway in cell cycle progression," Cell Cycle, vol. 2, no. 4, pp. 339-345, 2003.

[169] L. Rössig, A. S. Jadidi, C. Urbich, C. Badorff, A. M. Zeiher, and S. Dimmeler, "Akt-dependent phosphorylation of p21Cip1 regulates PCNA binding and proliferation of endothelial cells," Molecular and Cellular Biology, vol. 21, no. 16, pp. 5644-5657, 2001.

[170] G. Totzke, K. Schulze-Osthoff, and R. U. Jänicke, "Cyclooxygenase-2 (COX-2) inhibitors sensitize tumor cells specifically to death receptor-induced apoptosis independently of COX-2 inhibition," Oncogene, vol. 22, no. 39, pp. 8021-8030, 2003.

[171] E. P. Ryan, T. P. Bushnell, A. E. Friedman, I. Rahman, and R. P. Phipps, "Cyclooxygenase-2 independent effects of cyclooxygenase-2 inhibitors on oxidative stress and intracellular glutathione content in normal and malignant human B-cells," Cancer Immunology, Immunotherapy, vol. 57, no. 3, pp. 347-358, 2008.

[172] R. Mutter, B. Lu, D. P. Carbone, et al., "A Phase II study of celecoxib in combination with paclitaxel, carboplatin, and radiotherapy for patients with inoperable stage IIIA/B nonsmall cell lung cancer," Clinical Cancer Research, vol. 15, no. 6, pp. 2158-2165, 2009. 

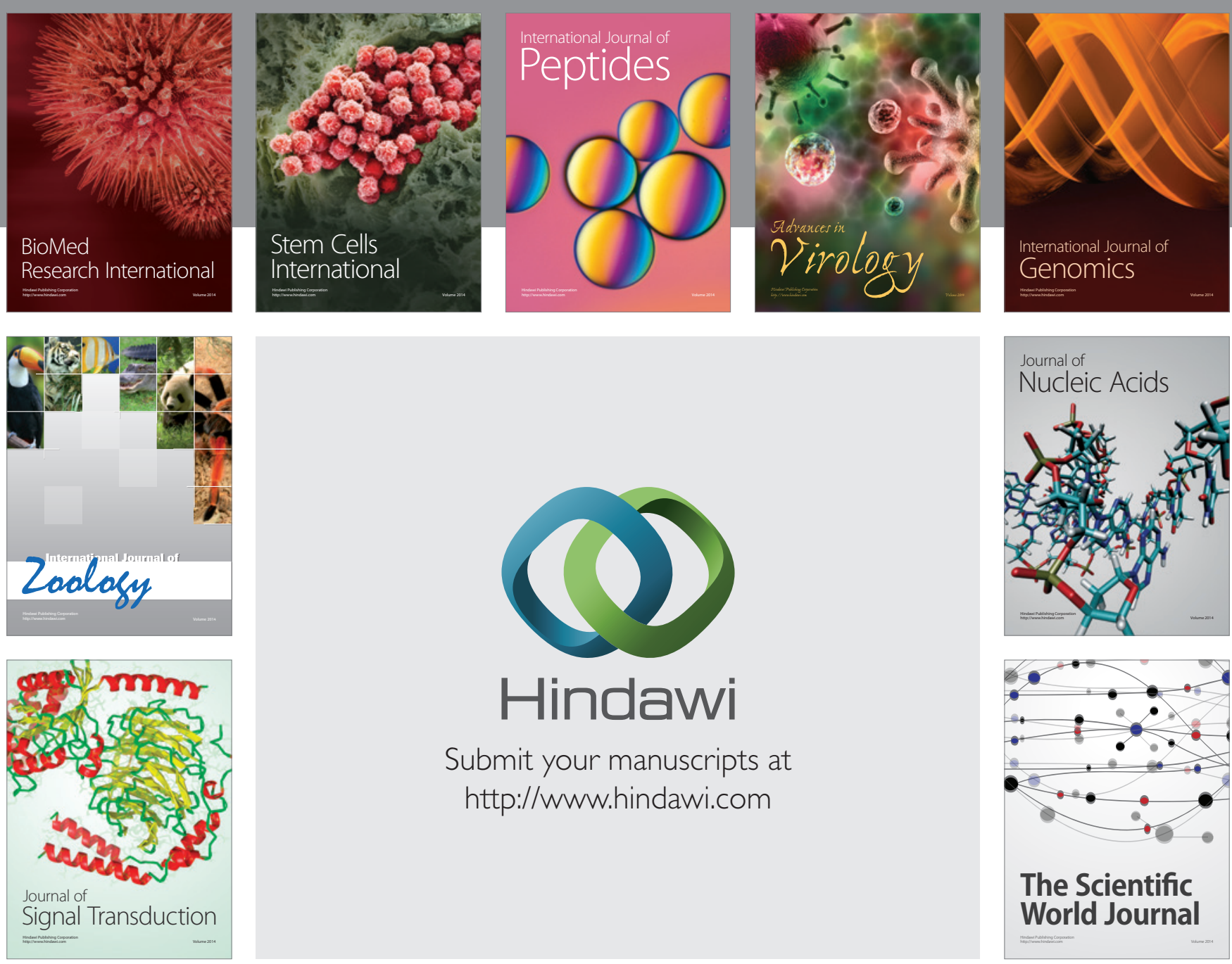

Submit your manuscripts at

http://www.hindawi.com
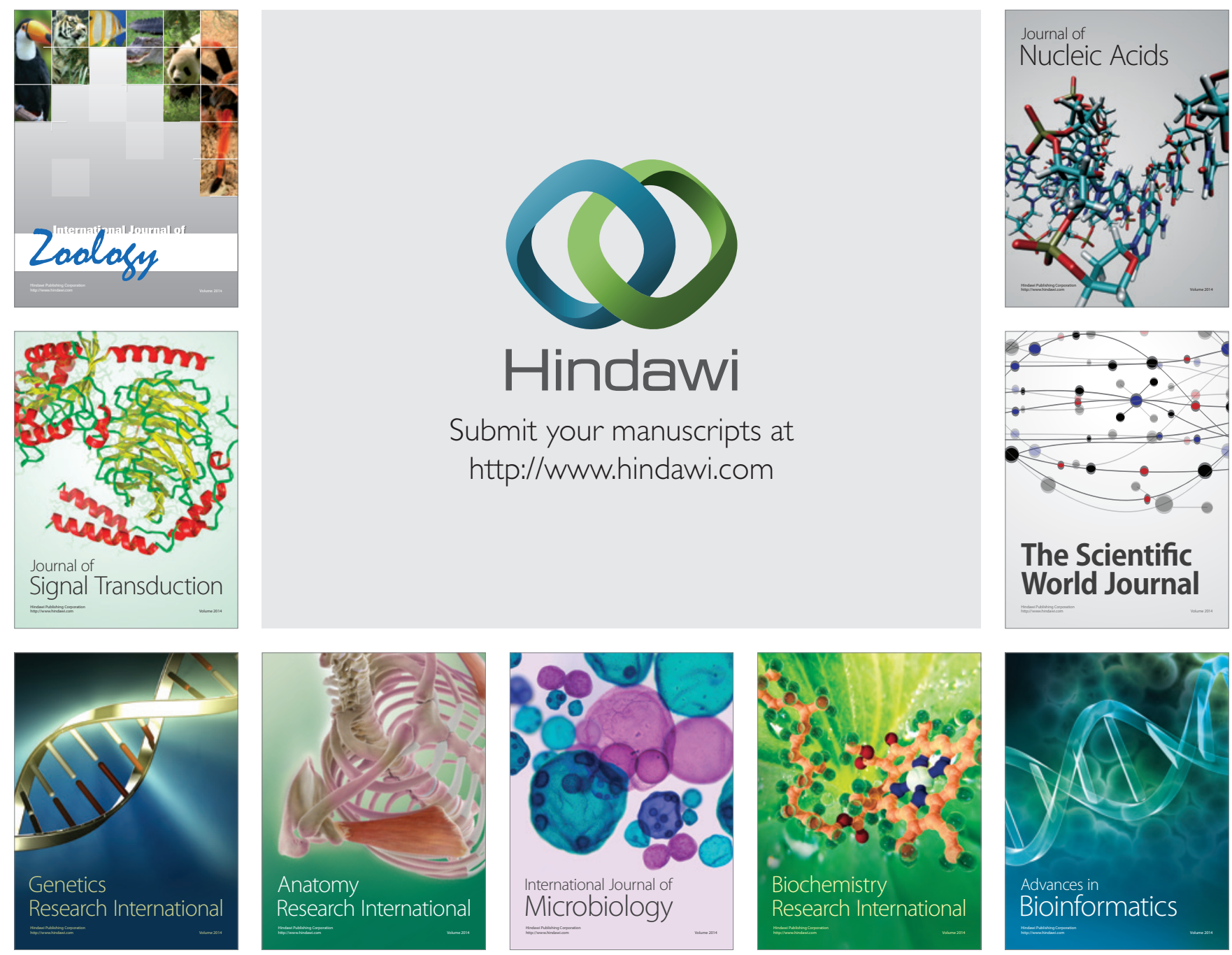

The Scientific World Journal
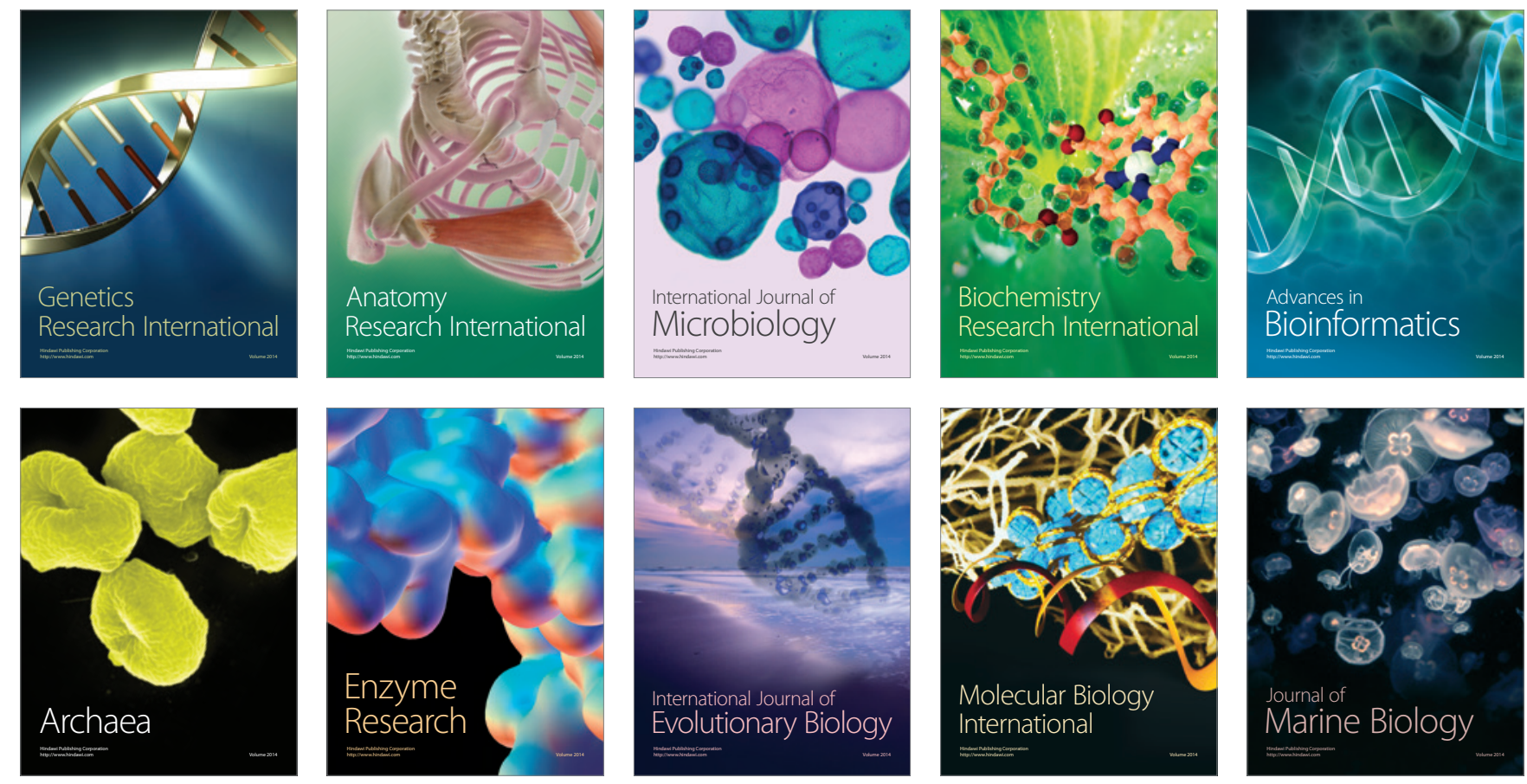